\title{
PAY-FOR-CREATIVITY: A SCHEME TO INSPIRE CREATIVITY
}

\author{
by
}

Sophia Janet Lam, BMOS, Western University, 2011

\author{
A thesis presented to Ryerson University \\ in partial fulfillment of the requirements for the degree of \\ Master of Science in Management \\ in the program of \\ Master of Science in Management, \\ Human Resources Management \& Organizational Behaviour
}

Toronto, Ontario, Canada, 2018

(C) Sophia Janet Lam, 2018 


\section{AUTHOR'S DECLARATION FOR ELECTRONIC SUBMITTION OF A THESIS}

I hereby declare that I am the sole author of this thesis. This is a true copy of the thesis, including any required final revisions, as accepted by my examiners.

I authorize Ryerson University to lend this thesis to other institutions or individuals for the purpose of scholarly research.

I further authorize Ryerson University to reproduce this thesis by photocopying or by other means, in total or in print, at the request of other institutions or individuals for the purpose of scholar research.

I understand that my thesis may be made electronically available to the public. 


\title{
PAY-FOR-CREATIVITY: A SCHEME TO INSPIRE CREATIVITY \\ By Sophia Janet Lam \\ Master of Science in Management in the program of Master of Science in Management, Human Resources Management \& Organizational Behaviour, Ryerson University, 2018
}

\begin{abstract}
Pay-for-Creativity is a type of compensation system designed to motivate and retain employees in an organization. Traditionally, professionals are motivated extrinsically, intrinsically, or a combination of both to think creatively. This study suggests that an individual's motivation alone does not lead to creativity or retention. Other factors contribute to creative thinking. This study argues that the most effective way to foster creativity is to provide individuals with a tangible reward.
\end{abstract}

Key words: Tangible reward, Motivation, Creativity, Retention 


\section{ACKNOWLEDGEMENTS}

I would like to take this opportunity to acknowledge the people who have supported and helped me throughout the past 16 months.

I would first like to thank my supervisor and co-supervisor, Dr. Fei SONG and Dr. Seung Hwan (Mark) LEE, for their invaluable assistance and insights leading to the writing of this paper. Fei, I want to thank you for your guidance and support throughout the program. I learned so much from you, from identifying a research question to developing hypotheses to test, and to executing the experiment. I also want to thank you for giving me an idea for the second study. Mark, thank you for being my mentor at the early stages of the study. Thank you for your kindness and patience. You provided me with the tools I needed to choose a direction and successfully complete my thesis.

Special thanks to my editor, Karen CAMPBELL from madproofingskillz.com. You have provided writing style support since my undergraduate years. Thank you again for proofreading this paper.

My sincere thanks also go to my parents (Peter LAM \& Alice LAM) and siblings (Angela B. LAM \& Dr. E. Tina LAM) for their wise counsel and sympathetic ear. You are always there for me.

Finally, a special thanks to my friends and colleagues. We were not only able to support each other by deliberating over our problems and findings, but also by talking about more than just our papers.

Thank you very much, everyone!

Sophia Lam 


\section{TABLE OF CONTENTS}

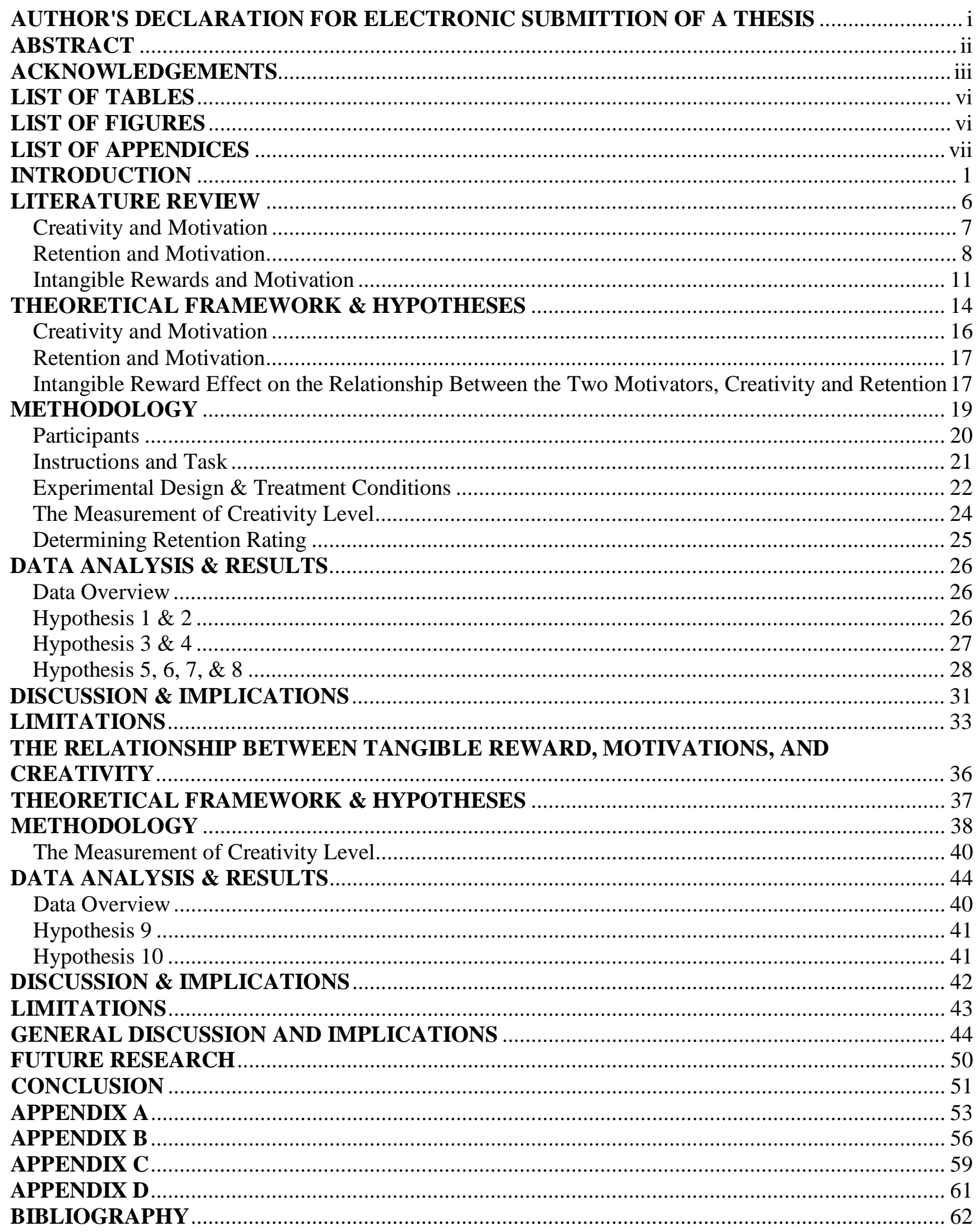




\section{LIST OF TABLES}

Table 1: Overall Mean, Standard Deviation, and Correlation..........................................................26

Table 2: Overall Mean, Standard Deviation, and Correlation........................................................42

\section{LIST OF FIGURES}

Figure 1.1: Theoretical model on intrinsic motivation and creativity............................................18

Figure 1.2: Theoretical model on extrinsic motivation and creativity..........................................19

Figure 1.3: Theoretical model on intrinsic motivation and retention............................................19

Figure 1.4: Theoretical model on extrinsic motivation and retention.............................................19

Figure 1.5: Mediating Role of intrinsic motivation on tangible reward and creativity.................29

Figure 1.6: Moderation role of intangible reward on intrinsic motivation and creativity.............29

Figure 1.7: Scatter-plot for the moderation role of intangible reward on intrinsic motivation and

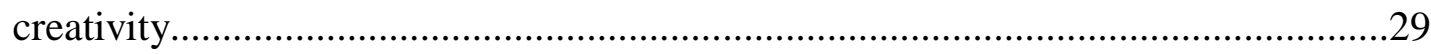

Figure 1.8: Moderation role of intangible reward on extrinsic motivation and creativity............ 29

Figure 1.9: Scatter-plot for the moderation role of intangible reward on extrinsic motivation and

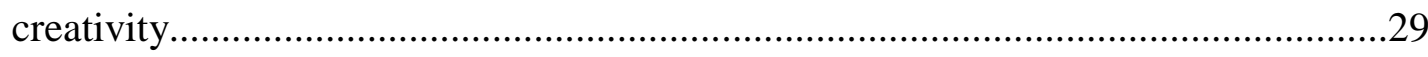

Figure 1.10: Moderation role of intangible reward on intrinsic motivation and retention.............31

Figure 1.11: Scatter-plot for the moderation role of intangible reward on intrinsic motivation and retention .31

Figure 1.12: Moderation role of intangible reward on extrinsic motivation and creativity............31

Figure 1.13: Scatter-plot for the moderation role of intangible reward on extrinsic motivation and retention. .31

Figure 2.1: Mediating role of intrinsic motivation on creativity. .42 


\section{LIST OF APPENDICES}

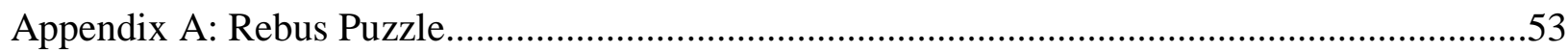

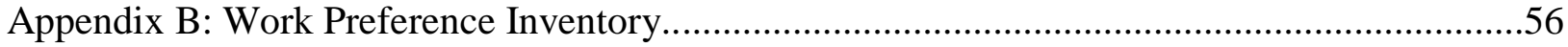

Appendix C: Instructions to Participants........................................................................59

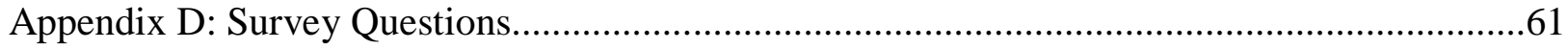




\section{INTRODUCTION}

When you work at a job, what does the word compensation mean to you? The traditional definition of compensation is a combination of base salary, incentives, and benefits.

Compensation also means different things to different stakeholders. While employees may perceive compensation as a reward for a job well done, the employer may perceive it as an exchange for a desired output. Nonetheless, employers use compensation as currency to attract, motivate, and retain employees (Milkovich, Newman, \& Milkovich, 2002).

According to the PayScale’s Compensation Best Practices Report (2016), for a number of years the biggest challenge for the majority of employers in any profession is retention. Some Human Resources (HR) professionals suspect that wages play a role in retaining employees. The PayScale report states that while 73\% of employers consider their employee compensation packages to be fair, only $36 \%$ of employees feel that they are paid fairly. In addition, the report also says that for the fifth year in a row, compensation is the top reason employees left companies (“PayScale’s 2016 Compensation Best Practices Report,” n.d.). Therefore, it is evident that wages are one of the deciding factors influencing employee decisions to stay with their employers. Rather than dedicating their time to looking for ways to improve employee engagement with their company, perhaps HR professionals should review the compensation structure and develop a better understanding of the motivational criteria that employees find most important.

Compensation is an important factor that affects retention. A lot of employers have implemented a mixture of variable pay, such as bonus plans and benefits, to entice talent. For example, aside from high salaries and comprehensive incentives, Google also offers its employees medical insurance, retirement pensions, free meals, and free use of exercise 
equipment. The fact that companies stress the importance of a compensation strategy, I suggest that a particular compensation structure—Pay-for-creativity—could have a significant impact on retention. Pay-for-creativity is based on the same principle as pay-for-performance with the exception of the measurement output. Pay-for-performance measures any desirable outcomes (i.e., number of units an individual can create in a given time). Pay-for-creativity specifically focuses on creativity.

Creativity is defined as "novel and useful products, ideas, or procedures that provide an organization with important raw materials for subsequent development and possible implementation” (Oldham \& Cummings, 1996). Amabile (1988) views individual creativity and organizational innovation as closely related systems. She defines creativity as "the production of novel and useful ideas by an individual or small group of individuals working together” and organizational innovation as "the successful implementation of creative ideas within an organization.” Oldham and Cummings (1996) explain that creativity could be a product or policy that is useful to the organization, and Amabile (1988) explains that creativity is an idea that is generated by an individual and can be successfully implemented in an organization; these two definitions provide a broad spectrum of creativity.

Building upon these two models, I define creativity as an individual or individuals generating a new idea or product that improves a process in an organization. Fagan (2004) states, "when creativity is the direct outcome, then it is considered as creative work since it requires the person to develop a novel idea for the application to the business process.” For example, in the Information Technology (IT) context, when creating a mobile application is the direct outcome of an IT development process, the application itself is considered a novel idea, because it requires the person to generate a new idea to change or add value to the current business model. 
There are studies that focus on measuring productivity (e.g., Cadsby, Song, \& Tapon, 2007), but I argue that productivity is more evident in the manufacturing sector. Professional industries, such as IT, are now relying on employee creativity to generate revenue. Simply producing the same technology is insufficient to increase business transactions. To be competitive, the nature of this business is a focus on quality over quantity. Creativity is a quality measurement. In the IT sector, creativity could refer to a new piece of software or a hardware application that does not exist in the market. For example, iTunes, the online music media player created by Apple Inc. in 2001, changed the way people listen to music. Instead of focusing on storage enhancement, Apple decided to create a platform that allows music lovers to access hundreds of albums at their fingertips.

On the other hand, Odom, Box, and Dunn (1990) find a strong positive correlation between employees working in an innovation-oriented culture and intent to remain in the company. Although this study is only focused on the transportation industry and on managerial positions, many companies appreciate their employees' artistic and creative talents. These employers consider personal characteristics as pivotal to their success, as their employees' characteristics help separate them from their competitors, creating a competitive advantage that is hard to mimic. However, some employers are reluctant to reward creativity, claiming that it is hard to measure. One of the reasons employers find creativity difficult to measure is that they do not have a measurement scheme. Very often, employers ask their employees to be creative, but they fail to communicate how creativity is to be measured. For example, in the IT context, creativity could mean a new idea that adds value to an existing product or a new perspective on an existing product. Employers need to communicate with their employees about how creativity is being measured, because without a measurement guideline, employees will lose their sense of 
direction. Since measuring creativity is an obstacle for employers, I include measurement in the pay-for-creativity model.

As discussed, pay-for-creativity has the same characteristics as pay-for-performance. It is a type of incentive system that uses monetary (stock options, cash bonuses, movie tickets, etc.) or non-monetary incentives (implicit praise from supervisors or a promise of potential career development) to motivate employees to achieve a desirable and measurable outcome (Cadsby, Song, \& Tapon, 2007). Companies understand the importance of creativity, yet they choose to measure quantity over quality. Although quantity is easier to define, it is the creative aspect of the job that excites employees. Pay-for-creativity allows employers to focus on creativity. Ideally, when employees understand what is being measured in a task (i.e., being creative), and the task is associated with a reward (tangible or intangible), then their performance improves and they are more likely to stay with the employer (Baker, Jensen, \& Murphy, 1988). Lawler (2000) and Cadsby, Song, \& Tapon (2007) agree that the pay-for-performance model is useful, provided that the model has a clear relationship between a significant amount of reward and the desired behaviour. In other words, individuals will achieve an assigned goal only when it is well defined and attached to a significant reward.

Rewarding is a common way to motivate an individual. The reward itself, whether it is tangible or intangible, acts as a stimulator. When a reward is given to an individual, it should trigger the individual's intrinsic or extrinsic motivation, thereby allowing them to achieve a specific goal. A tangible reward is defined as a monetary item or perspective that one can hold or consume. In a organizational context, it could mean a pay raise or a promotion. An intangible reward is a statement of recognition (Dzuranin \& Stuart, 2012). An example of a tangible reward is the promise Houston-based Hailcorp Energy Company made to its staff in 2010: if the 
company were to double its production rate by 2015, every employee would receive a cheque for $\$ 100,000$. In 2015, the goal was achieved and the company delivered its promise by giving the large bonus to all employees. ("Hilcorp Energy gives employees \$100,000 bonuses for meeting five-year goals,” n.d.). An example of an intangible reward is a program entitled, "Catch Someone Doing Something Right” by NetApp. NetApp assumes that simply thanking employees would improve employee morale, thereby having a positive impact on performance. The idea of the program is that the CEO will personally recognize employees who perform their jobs well (“How NetApp became one of the world's best employers,” n.d.). At NetApp, employee performance is tied to respect and appreciation. Several empirical studies provide evidence that initiatives like that of NetApp are effective. These studies have identified a positive relationship between extrinsic and intrinsic rewards and employee performance (Akta, Sachu, \& Ali, 2012; Kachelmeier \& Williamson, 2010). However, these studies are limited to people, space, and time. In addition, they also do not have a direct link to our research focus on creativity and retention. Initially, this study focused on intangible rewards. I explicitly address two questions: do intangible rewards have an impact on intrinsic motivation and/or extrinsic motivation? More importantly, do intrinsic and extrinsic motivation have an impact on creativity and retention? In examining these questions, I found that to a certain degree motivations contribute to retention and creativity and creativity measurement leads to retention. Findings from the first study suggested that there might be a relationship between tangible reward and creativity. Therefore, the second study was created to examine this idea. I found that tangible reward leads to creativity. However, an intrinsic motivator does not fully mediate the relationship between tangible reward and creativity. 
To explore these questions, I developed theoretical models (see fig. 1.1, 1.2, 1.3, 1.4, \& 1.5) based on the existing literature on rewards, motivations, creativity, and retention. Then, using laboratory studies, I examined the relationship between the two types of motivation (intrinsic and extrinsic) to retention and creativity. Subsequently, I explored the moderation and mediation effect of intangible/tangible rewards on those relationships.

\section{LITERATURE REVIEW}

Several researchers agree that the most effective compensation system to improve performance and retention is pay-for-performance (Durham \& Bartol, 2000; Cadsby, Song, \& Tapon, 2007). Examples of a pay-for-performance plans are incentives, variable pay, and merit pay. The principle of the system is offering a reward for measured performance that is within the control of individuals. The system contributes to performance and retention through two mechanisms. First, it assumes a reward will positively influence an individual's motivation. Second, it aligns with individuals' expectations of how they would like to be compensated. This system works well under two conditions: when an individual perceives the procedure and the method of distribution as fair and when the end goal, if any, is achievable. Price and Mueller (1981) come to the similar conclusion that when individuals perceive pay to be fair, it becomes a motivator for that individual to stay with the company. Therefore, holding the first condition constant, when an individual is rewarded for a quantifiable outcome (e.g., creativity) then presumably the individual's performance improves and their likelihood of staying increases.

Different rewards have different impacts on intrinsic and extrinsic motivations. There are two types of reward: intangible and tangible. While some researchers claim that a tangible reward has a better influence on extrinsic motivation (i.e., Jenkins, Mitra, Gupta, \& Shaw, 1998), other researchers find it diminishes intrinsic motivation, negatively impacting the individual's 
performance (Amabile, 1996). Still other researchers find that an intangible reward is highly associated with improved performance, leading to retention (Durham \& Bartol, 2000). In sum, these researchers agree that there is a relationship between reward and motivation.

\section{Creativity and Motivation}

Some researchers believe that extrinsic motivation can lead to better performance (Gagne \& Forest, 2008). Extrinsic motivation is often defined as doing an activity for an instrumental reason. Gagne and Forest (2008) suggest that extrinsic motivation can be internalized, where the individual does an activity solely to obtain a reward or to avoid punishment (external regulation) or for self-worth, such as to boost one's ego or to avoid guilt (introjected regulation) (Gagne \& Forest, 2008; Ryan 1995). Stimulus-response theory suggests that individual motivation can be redirected through an incentive that is either tangible or intangible and that is linked to a specific performance (Wilbel, Rost, \& Osterloh, 2010). Numerous studies support this theory. For example, Lazear (2000) refers to the case of Safelite, the largest windshield manufacturer in the US. The company's productivity increased by $40 \%$ after the company replaced hourly wages with a piece rate.

Most studies on stimulus response measure quantity alone. In terms of quality, learned industriousness theory assumes that the expectation of reward can improve performance in any dimension, including creativity (Eisenberger, 1992). According to this theory, when individuals are rewarded for carrying out a task, they must learn which dimensions of performance are required. Therefore, the expectation of being rewarded triggers the individual's extrinsic motivation, leading them to perform as required. This theory only holds true when two elements are presented in a task: the measurement outcome (i.e., creativity) has to be explicitly

communicated to the individual and the individual has to believe that the measured performance 
is required for the reward. Several studies support this theory, finding that rewards contingent on creativity increase extrinsic motivation (Eisenberger \& Armeli, 1997; Eisenberger \& Rhoades, 2001).

On the other hand, some researchers argue that intrinsic motivation is a better predictor of creative performance (Deci, 1972). Intrinsic motivation refers to doing an activity for its own sake, because one finds the activity inherently interesting and satisfying (Gagne \& Forest, 2008.) Deci (1972) states that a person is intrinsically motivated to perform an activity if they perform despite the absence of an apparent reward aside from the activity itself or the feelings that result from the activity. According to Gagne \& Forest (2008), intrinsic motivation can be categorized as identified regulation and integrated regulation. Identified regulation refers to doing an activity one sees as valuable or meaningful; the action is autonomously regulated. Integrated regulation refers to the activity becoming habitual and part of the person's sense of self (Gagne \& Forest, 2008). Deci (1972) suggests that when the job is perceived as interesting and the individual has the freedom to be creative, then the individual will be intrinsically motivated to perform better. Therefore, a creative job should be structured to boost intrinsic motivation. Furthermore, Shalley et al. (2000) find that the level of creativity required in a job is positively associated with the amount of autonomy and complexity and the demands of the job. When individuals are intrinsically motivated in their work, all of their attention and effort should be focused on their job, making them more persistent and more likely to consider alternatives, which should lead to higher levels of creativity and lessen their intention to leave the company (Shalley, 1995; Shalley, Gilson, \& Blum, 2000).

\section{Retention and Motivation}


Employee retention refers to the ability to keep employees within the company for as long as possible. The common approach to measuring retention is the separation rate, which is calculated by the number of members who left during a period divided by the average number of employees during that period (Mowday, Porter, \& Steers, 2013). Employee departures can be divided into two categories: involuntary and voluntary. Sometimes, involuntary turnover is unavoidable, for example, during downsizing when an organization's economic conditions or strategic planning efforts are challenged and the organization has no other choice but to terminate employees in order to realign its business strategic plan. Other types of involuntary leaves include dismissals, where an individual's performance is below a satisfactory level or due to insubordination (McElroy, Morrow, Rude, 2001). On the other hand, voluntary leave refers to an individual deciding to leave a company for personal reasons. Trevor (2001) states that voluntary turnover has generated a vast amount of scholarly interest; numerous articles address the extent of, the cost of, and methods for reducing voluntary turnover. This study also focuses on voluntary turnover.

Some researchers argue that extrinsic motivation is enough to entice individuals to stay with a company (e.g., Griffeth, Hom, \& Gaertner, 2000; Miller, Hom \& Gomez-Mejia, 2001). As discussed, an instrumental reason is required to trigger extrinsic motivation. Griffeth et al. (2000) examine factors that cause employees to resign and discover that the effect of pay and compensation forms, such as fringe benefits, promote the extrinsic motivation, thereby motivating them to stay. Porter and Steers (1973) agree that rewards, such as pay and benefits, are related to retention, because employees are sensitive to receiving fair rewards for their efforts and may leave when opportunities to receive greater rewards exist elsewhere. However, Hausknecht, Rodda, and Howard (2009) suggest that extrinsic rewards, such as competitive 
wags, health benefits, retirement contributions, and incentive plans, do not contribute to retention. They argue that high performing employees would not be motivated to stay because of the rewards and benefits. They would stay for other reasons, such as advancement opportunities or for intrinsic value such as job satisfaction. Nonetheless, these researchers agree that a form of instrumental reasoning can help to promote extrinsic motivation, which will indirectly lead to retention.

According to Ramlall (2004), employees are intrinsically motivated when they perceive their tasks to be interesting and challenging. The idea here is that the task itself is the employee's motivator. Therefore, when employees enjoy what they do, they tend to stay longer (Hausknecht, Rodda, \& Howard, 2009; Price \& Mueller, 1981). Research suggests that challenging jobs enhance motivation. Variety, autonomy, and decision-making authority are three ways of adding challenge to a job. Job enrichment and job rotation are two ways of adding variety and challenge (Ramlall, 2004). When employees are dissatisfied with their task, they tend to leave the company. It is important to note that intrinsic motivation refers to feelings related to the task and task performance but not overall satisfaction with the position. Ramlall suggests that job motivators should be embedded into the job design (Ramlall, 2004). According to Herzberg et al. (2011), satisfaction would occur only as a result of the use of motivators such as achievement, recognition, and the work itself (Herzberg, Mausner, \& Snyderman, 2011). This is why challenging work, job enrichment, job enlargement, and opportunities for advancement can improve company retention.

Furthermore, studies show that when employees intrinsically enjoy the actual work, they report higher job satisfaction (Eby \& Freeman, 1999; Harkins \& Petty, 1982). However, Thatcher et al. (2006) find that only autonomy (employees possessing the flexibility to structure 
tasks), skill variety (work is meaningful when employees can use multiple skills), and supervisory satisfaction (referring to management interaction and employee supervision) are associated with intrinsic motivation. They agree that there is a positive and direct link between intrinsic motivators and job satisfaction and retention.

\section{Intangible Rewards and Motivation}

There are mixed research findings on the relationship between the two motivators and creativity and retention. However, the intangible reward effect on the two motivators, creativity, and retention has yet to be explored. Tangible and intangible rewards may have distinct effects on motivation. There are many studies focused on the effects of tangible rewards (Kachelmeire and Williamson, 2010; Cadsby, Song, \& Tapon, 2007) and others have focused on the effects of external events such as threats (Deci, 1972; Deci \& Cascio, 1972) and deadlines (Amabile, DeJong, \& Lepper, 1976). There are also studies exploring the relationship between intangible rewards and behaviour, but they are mostly bound by person, time, and space. Research has also shown that an intangible reward has a greater effect on motivations than a tangible reward (Deci \& Cascio, 1972). Study 1 focuses on the effects of intangible rewards on motivations, creativity, and retention while study 2 explores the effects of tangible rewards on motivations, and creativity.

An intangible reward is difficult to observe and measure, and it is usually generated from other actors in the social environment such as peers and leaders. Intangible rewards for creativity offer social recognition for creative performance, including informal acknowledgement, attention, praise, approval, or genuine appreciation for a job well done (Peterson \& Luthans, 2006; Yoon et al., 2015). In this study, I examine positive feedback on performance as an intangible reward. 
Positive performance feedback will enhance perceived competence, thus enhancing intrinsic motivation. In a meta-analysis, Deci tests how feedback enhances intrinsic motivation (Deci, 1971). He suggests that not all feedback improves intrinsic motivation. Generally, there are two kinds of feedback: controlling and informational. An example of controlling feedback is a statement that contains the word "should," for example: "Excellent. You should keep up the good work.” Informational feedback contains only results or scores along with information about how individuals perform. Studies show that controlling feedback leads to less intrinsic motivation, while informational feedback suggests otherwise (Ryan, 1982; Pittman, Davey, Alafat, Wetherill, \& Kramer, 1980).

However, one of the drawbacks of positive feedback, according to Cognitive Evaluation Theory (CET), is that the controlling aspect of controlled feedback may lead people to engage in behaviours specifically to gain praise, which has the potential to increase extrinsic motivation (Deci, Koestner \& Ryan, 2001). This is consider a drawback because the mechanism behind an intangible reward (i.e. positive feedback) is to trigger one intrinsic motivation. However, when one sees the positive feedback as a tangible reward, it triggers the extrinsic motivation. Since extrinsic motivation can only be triggered by a tangible reward, presumably an intangible reward will decrease extrinsic motivation unless one sees the intangible reward as a tangible reward. For example, when an individual requires a positive feedback in order to perform at a certain standard, the intangible reward, positive feedback, in this example becomes an tangible reward. Hull (1943) studies the relationship of reward to behaviour using a simple stimulusresponse mechanism. In his study on principles of behaviour, Hull finds that rewards perform several important functions. For example, a reward may reinforce, and thus influence, the individual's productivity, or it can serve as an incentive that can extrinsically or intrinsically 
motivate an individual to produce at a certain level. Hull argues that a reward is positively correlated to motivations and creativity. However, the Yerkes-Dodson Law suggests that increasing the level of motivation by a reward will enhance performance up to a certain threshold, but after that, further motivation will result in poorer performance (Yerkes \& Dodson, 1908). This finding is similar to the findings of Kachelmeire and Williamson (2010), where they discover that rewards have limitations.

In an experiment that includes creativity as a measured performance variable in addition to quantity, Kachelmeire and Williamson (2010) conclude that participants who identify as creative are inspired to be more creative initially when a reward is presented. However, in aggregate, participants’ creativity levels remain static when creativity level reaches a certain threshold. This phenomenon is explained in the literature on creativity in psychology and management. Amabile (1996) suggests that creativity does not generate results simply from trying harder even with a reward presented. Amabile and other researchers suggest that individual creativity cannot be triggered by external rewards when the individual lacks domainrelevant and creativity-relevant skills (Amabile, 1996; Prabhu, Sutton \& Sauser, 2008). According to Amabile (1994), domain-relevant skills refer to factual knowledge, technical skills, and special talents in the domain of the field. Creativity-relevant skills include a cognitive style favourable to taking new perspectives on problems that are embedded in the individual's personal traits. In other words, an individual needs to have the technical skill to be creative in a given field, and that individual needs to be intrinsically motivated to think outside the box.

In fact, some studies show that external rewards may have a negative impact on creativity. For example, Amabile suggests that external rewards reduce intrinsic motivation by lessening the perception of personal freedom (Amabile, 1983; Deci \& Ryan, 1985). Amabile and her 
colleagues view reward as an unpleasant constraint on behaviour, as it shifts the individual's attention to focus on the rewards (Amabile, 1983; Amabile \& Hennessey, 1988).

On the other hand, Yoon et al. (2015) suggest that individuals respond better to intangible rewards. As discussed, intangible rewards for creativity offer social recognition for creative performance, which includes positive feedback for a job well done (Peterson \& Luthans, 2006). Eisenberger \& Rhoades (1999) find that this type of recognition signifies a high degree of achievement and a perception of competence.

In addition, Rhoades and Eisenberger (2001) find that intangible incentives increase creativity by promoting self-determination and intrinsic task interest in accordance with CET (Rhoades \& Eisenberger, 2001; Eisenberger \& Aselage, 2009; Deci, Koestner, \& Ryan, 2001). This theory proposes that intrinsic motivation is based on the psychological need for competence and self-determination. According to CET, there are a number of ways to increase intrinsic motivation. For example, Eisenberger \& Aselage (2009) argue that when the individual is given the freedom to choose between whether to perform to obtain the reward or to decline the reward and not act as requested, then the individual will promote self-determination, increasing the intrinsic motivator.

\section{STUDY 1: THEORETICAL FRAMEWORK \& HYPOTHESES}

In terms of compensation structure, Cadsby, Song, and Tapon (2007) examine the impact of pay-for-performance versus fixed salary compensation on sorting and incentive effects. Although, this article provides important information on incentive effects, I am unable to adopt their framework simply because the measured variable is different. I examine the effect of intangible reward on the two motivators (intrinsic and extrinsic), creativity, and retention while Cadsby, Song, and Tapon (2007) focus on the sorting effect. 
Similarly, Durham and Bartol (2000) discuss the principle of pay-for-performance, providing a definition and its two main functions: to motivate and retain employees in an organization. Since their interest lies with rewards at the individual, small group, and organizational level, their theoretical framework is not relevant either.

In terms of creativity and motivation, Amabile (1988) created a partial descriptive model to examine factors influencing creativity and innovation in organizations. The aim of the research project is to provide a framework that a company should consider using in the process of organizational innovation (Amabile, 1988; 1996). This framework exposes one dimension of how creativity can be motivated but does not explore its relationship to retention.

Similarly, Eisenberger and Shanock (2003) use many studies to explore the effects of rewards on creativity. They conclude that rewards can increase intrinsic motivation, which will improve creativity. Choi’s model (2004) uses individual characteristics, including intrinsic and extrinsic motivation, along with social factors, such as supportive leadership and open group climate, to examine the impact of creativity. In addition, Eby and her colleagues use different variables (meaningful task, responsibility, knowledge, and empowerment) to examine intrinsic motivation. Furthermore Fagan (2004) and Gagne and Forest (2008) explore the impact of environmental factors and factors such as procedural justice and company culture on creativity and motivation. These models offer some knowledge as to how motivation factors influence creativity; however, they do not draw a connection between motivation and retention.

In terms of retention, Hausknecht, Rodda, and Howard (2009) use content analysis to identify several factors that cause employees to stay with a company. These factors are mainly extrinsic motivators that are either tangible or intangible, for example, advancement opportunities, pay, benefits, and location. The research explains the relationship between 
extrinsic rewards and retention, but does not explain how this influences the creativity level of an individual. Abbasi and Hollman (2000) explain the consequences of turnover and provide reasons at the organizational level for why employees choose to leave a company. Hiring practices, managerial style, lack of recognition, and toxic workplace environments were some of the factors referenced in the article.

My phenomena of interest are retention and creativity. Specifically, I want to observe how an intangible reward affects the relationship between the two motivators (intrinsic and extrinsic), retention, and creativity. The researchers profiled above offer some theoretical perspectives on pay for compensation models, motivation, creativity, and retention. Although some theoretical frameworks offer insights on the present topic, I am unable to adopt any of them, because none of them really make the connections between intangible reward and its effects on retention and creativity. Based on the existing theoretical perspectives, I set out to develop my own theoretical models (see fig 1.1, 1.2, 1.3, and 1.4).

I have provided a definition for pay-for-creativity in our research project. Then, based on the existing literature, I explored the relationship between pay-for-creativity and the two motivators. Next, I defined our scope of retention, focusing on voluntary turnover. From the existing theoretical perspectives, I discovered the effects of intangible rewards on the two motivators, retention, and creativity. From this basis, I offer the following hypotheses for testing:

\section{Creativity and Motivation}

There are two motivators that increase creativity. When there is no apparent reward associated with a task and an individual is able to achieve an assigned goal, then the individual is intrinsically motivated to perform (Gagne \& Forest, 2008). On the other hand, when an individual achieves a goal for an instrumental reason, then the individual is extrinsically 
motivated (Gagne \& Forest, 2008; Ryan 1995). Regardless of the type of motivation, the end goal-creativity — is achievable when it is well defined and explicitly communicated to the individual.

H1 - There is a positive relationship between intrinsic motivation and creativity. (Fig. 1.1)

H2 - There is a positive relationship between extrinsic motivation and creativity. (Fig. 1.2)

\section{Retention and Motivation}

When an individual perceives a task as interesting or challenging, he/she will stay with the company longer in order to preserve the excitement (Hausknecht, Rodda \& Howard, 2009; Price \& Mueller, 1981). Therefore, the individual is intrinsically motivated. On the other hand, when an individual decides to stay with a company to perform a task for an instrumental reason, such as a reward, then the individual is extrinsically motivated. Both intrinsic and extrinsic motivators lead to retention. Therefore, an incentive should be given depending on the individual's motivation orientation.

H3- There is a positive relationship between intrinsic motivation and retention. (Fig. 1.3)

H4 - There is a positive relationship between extrinsic motivation and retention. (Fig. 1.4)

\section{Intangible Reward Effect on the Relationship Between the Two Motivators, Creativity and Retention}

Research shows that intangible rewards yield better benefits than tangible rewards with respect to motivation (Deci \& Cascio, 1972). There are multiple angles of intangible rewards to the relationship with motivators, creativity, and retention. According to the S-R mechanism, an intangible reward will strengthen the individual's intrinsic motivation, thereby increasing creativity (Hull, 1943). However, an intangible reward has the opposite effect on extrinsic 
motivators. Amabile (1996) believes that an individual's creativity cannot be triggered by a reward, because the individual will shift his/her focus to the reward itself.

H5 - Intangible rewards positively moderate the relationship between intrinsic motivation and creativity. (Fig. 1.1)

H6 - Intangible rewards weaken the relationship between extrinsic motivation and creativity. (Fig. 1.2)

In terms of retention, an intangible reward promotes an intrinsic motivator (Deci, 1971), which will lead to an increase in retention. However, an intangible reward weakens an extrinsic motivator (Amabile 1996). As discussed, extrinsic motivators are associated with retention. Therefore, when extrinsic motivators are weakened, retention decreases.

H7 - Intangible rewards positively strengthen the relationship between intrinsic motivation and retention. (Fig.1.3)

H8 - Intangible rewards weaken the relationship between extrinsic motivation and retention. (Fig. 1.4)

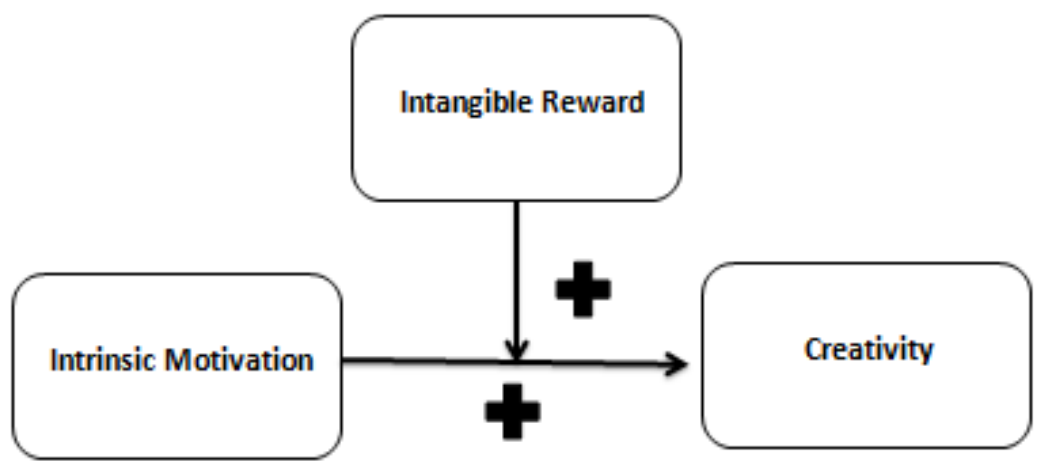

Figure 1.1: Theoretical model on intrinsic motivation and creativity 


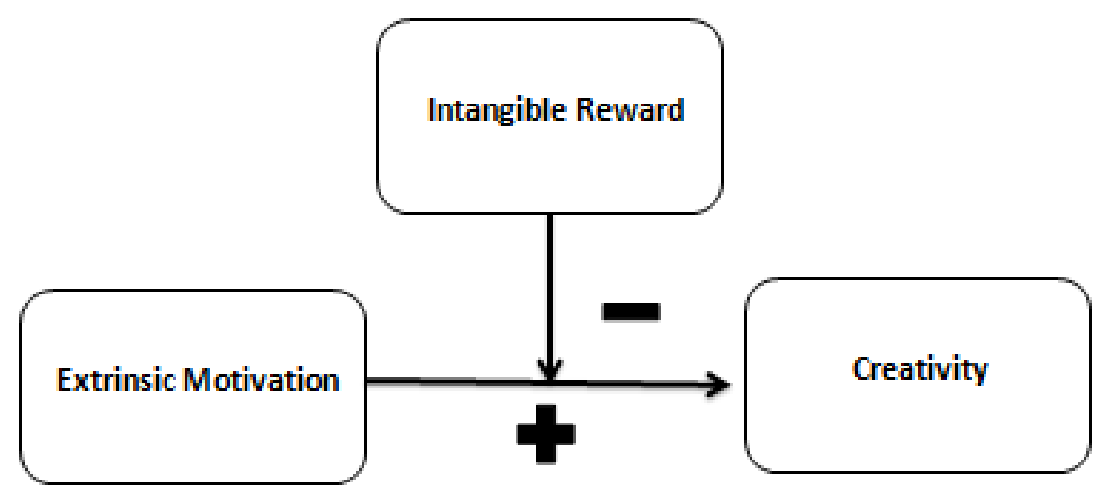

Figure 1.2: Theoretical model on extrinsic motivation and creativity

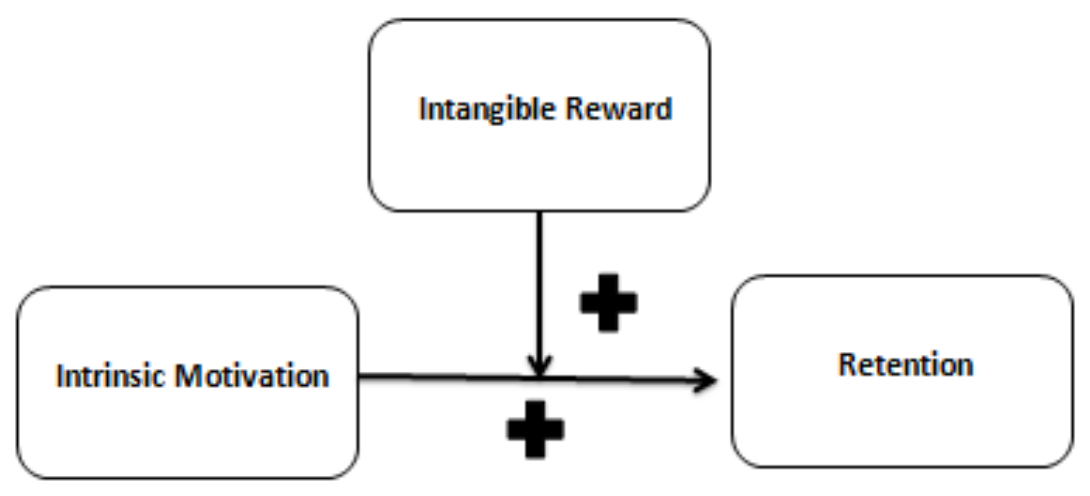

Figure 1.3: Theoretical model on intrinsic motivation and retention

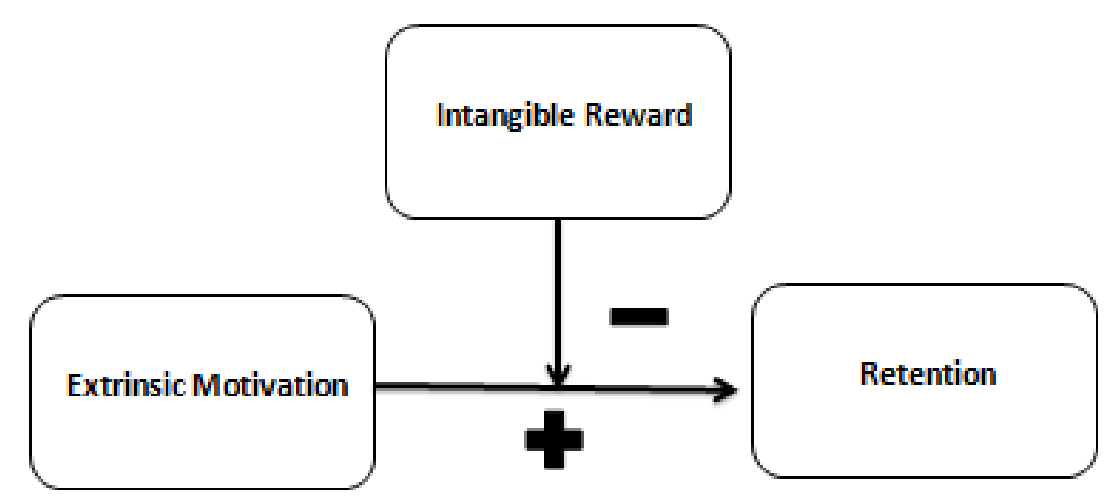

Figure 1.4: Theoretical model on extrinsic motivation and retention 


\section{STUDY 1: METHODOLOGY}

\section{Participants}

I randomly recruited 69 professionals on the street from the downtown Toronto area (between Dundas \& Yonge Street) to participate in one of sixteen compensated research sessions (the number of participants varies in each session) from which I obtained 57 usable results. There were 12 people who did not meet the study requirements. These participants were either did not earn more than the provincial minimum wage or they did not have a job. Those eligible for the study self-identified as creative individuals and have a casual, part-time, or fulltime professional/managerial job that yields more than the minimum wage. I selected this group of professionals is because the study focus is in a organizational setting. Therefore, participants must have a job to take part in the study. As of 1 October 2016, the minimum wage in Ontario was $\$ 11.40$ per hour. I intentionally selected professionals who earn more than the minimum wage for two reasons. First, minimum wage is part of the Employment Standards Act (ESA), which almost all companies in Ontario have to follow. Second, according to Statistics Canada, in July 2017, the average hourly wage in Ontario was \$17.30 for part-time employees and \$27.52 for full-time employees (Government of Canada, 2017). Therefore, the occupation I decided to focus in the study must yield the minimum wage. Participants in each session worked independently in a classroom setting, where they sat side-by-side or opposite to each other depending on the number of participants present in each session. The reason I conducted the study in a group setting is because in reality individuals are never isolated in a organizational context. 


\section{Instructions and Task}

Based on a similar study from Kachelmeier, Reichert, \& Williamson (2008), the experiment instructions inform participants that they will construct "rebus puzzles," defined as "a kind of riddle in which words and/or diagrams are used to present a familiar phrase.” According to Kachelmeier, Reichert, \& Williamson (2008), Griggs (2000) is the only one who uses rebus puzzles in the educational psychology application to illustrate psychometric testing. Unlike Griggs (2000), Kachelmeierm, Reichert, \& Williamson (2008) ask their participants to design rather than solve rebus puzzles in the study. This provides an opportunity for participants to think creatively without boundaries imposed by rules. In addition, not all participants are good at solving problems. According to Hennessey \& Amabile (1988), social and environmental factors play major roles in an individual's creative performance. They further suggest that individuals are most creative when they find the task interesting and enjoyable. Therefore, I hope that by asking participants to create their own puzzle, they will find the task more enjoyable.

As indicated in appendix A, common to all experimental conditions is the experiment instructions. I provide 10 examples of rebus puzzles and their corresponding solutions (mostly adapted from Kachelmeier, Reichert, \& Williamson, 2008), emphasizing that there are different types of rebus puzzles. Along with the written instructions, I also verbally explain the task objective: "There is no set of rules on the kinds of rebus puzzles you can create. We value the creativity of those puzzles” (i.e., puzzles that are original ideas, innovative, and clever). In this manner, I direct the participants to focus and pay attention to being creative. I adopted this strategy based on the findings of Shalley (1991) that individuals need to have their attention and effort focused on either a “do-your-best” or difficult creativity goal in order to be creative. By 
controlling one of the dependent variables (creativity), I can truly measure the impact of the independent variables (i.e., experimental conditions).

During the task, participants are asked to design puzzles on 3 x 5 inch index cards, placing the puzzle on one side and its solution on the other. Participants are instructed to put their completed puzzle into an "output box," subject to the understanding that once in the box, a puzzle cannot be removed. The last part of the instructions are explanations of the logistics of the experiment.

\section{Experimental Design \& Treatment Conditions}

There are three parts to the experiment. The first part is designed for practice, where participants will have 15 minutes to create five puzzles (3 minutes per puzzle). We introduce time pressure, because Ramlall (2004) suggests that participants will be intrinsically motivated when they perceive the task to be interesting and challenging. By including a time boundary I could measure the other dependent variable (retention). Furthermore, this part of the study is needed to ensure participants understand the requirements and get familiar with the task.

The second part of the study requires participants to complete a short survey (see appendix B). There are two components to the survey. The first component is used to assess the intrinsic and extrinsic motivational orientations of the participants. I adapted the Work Preference Inventory (WPI) instrument from Amabile et al. (1994), because it is well established and has been tested in various settings (e.g., Stuhlfaut, 2010; Loo, 2001). All items are measured on four-point Likert scales ranging from 1 (never or almost never true of you) to 4 (always or almost always true of you). There are 15 items to measure intrinsic motivation $(\alpha=.68)$ and 15 items to measure extrinsic motivation ( $\alpha=.66$ ). A sample item of intrinsic motivation is "I enjoy tackling problems that are completely new to me" and "The more difficult the problem, the more 
I enjoy trying to solve it.” A sample item of extrinsic motivation is "I am strongly motivated by the money I can earn” and "I want other people to find out how good I really can be at my task."

In addition, the WPI also measures four sub-factors: enjoyment, challenge, outward, and compensation. These factors are associated with the primary factors. Enjoyment $(\alpha=.60)$ and challenge $(\alpha=.68)$ are associated with intrinsic motivation, while outward $(\alpha=.71)$ and compensation $(\alpha=.22)$ are associated with the extrinsic motivation. The second component consists of five demographic questions that are useful for verifying participants' eligibility and for data analysis.

The study has two conditions: tangible and intangible reward. The two conditions are fairly equally distributed amongst the participants (30 intangible and 27 tangible). In the condition with tangible reward, the instruction informed participants that they would earn an additional $\$ 2$ for every puzzle that exceeded the assigned goal of 4.5 on a 5-point scale. The goal has to be set above the grade given in the practice round, which was 3.0 out of 5 . I chose 4.5, because I believe there is always room for improvement. In the condition with intangible reward, participants receive handwritten feedback that reads, “Great Job! Keep up the good work” with a happy face drawn for a boost of encouragement. This feedback is given to the participants once-after the survey is completed and before the final part of the experiment begins.

Before distributing the survey, participants are advised that the puzzles created in the practice round are to be graded by an unnamed professional who is specialized in creativity. After the survey is completed, all participants receive an envelope with three index cards in the following order: a grade from the practice round, a condition, and an assigned goal. In order to control the independent variable, all participants are given the same grade (3.0/5.0) and goal (4.5/5.0), regardless of the condition received. I am unaware of any study that focuses on the 
impact of the order of the index card presentation. Nonetheless, it is a good idea to keep the order consistent.

The last part of the study is the main focus and is similar to the first part, where participants are asked to create puzzles within a time limit (three minutes per puzzle). However, there are two differences from the initial part of the experiment: all participants have a goal to achieve, and participants can stay for as many rounds as they wish. As discussed in the literature, I expect that the goal setting in the final part of the experiment will positively influence participants' intrinsic motivation. To test the impact of the treatments on retention, participants are free to leave at any time.

After finishing the task, participants are told that the additional phenomenon of interest in the study was retention. All participants, regardless of which conditions they received in the study, are rewarded cash compensation of $\$ 15$ on the day of participation. They are then dismissed with a request not to discuss the experiment with others.

\section{The Measurement of Creativity Level}

To obtain the dependent variable for creativity, I need unbiased ratings of creativity. I invited two volunteers to perform the task. I chose to use convenience sampling, because I believe that anyone who can read and understand English can perform the task. Amaible (1996) suggests using several raters to reduce noise and to ensure reliability.

There are total of 668 rebus puzzles submitted by 57 participants. We shuffled these cards to collect an individual rating by two graders who were blind to the treatment conditions. The cards were shuffled and handed to the graders to ensure that the identity of the creators of the index cards were somewhat blinded to the graders. This means that a participant's set of 
completed cards were shuffled well enough that they would not be found back-to-back when the grader considered them individually.

The graders performed the task separately and on their own time. The first grader performed the task in a single session of six hours, while the second grader completed it in two sessions of four hours. The ratings used to grade these cards were on a 1 (lowest creativity) to 5 (highest creativity) scale.

The graders read the same common instructions the participants read, without the final section about compensation that varies by treatment condition. In addition, rubric guidelines were verbally given: "1- No creativity at all, closer to the examples that are illustrated in the instructions. 3 - Average, somewhat closer to the examples that are illustrated in the instructions. 5- Very original, innovative, and clever.” To calculate the average creativity score, I added the total scores of graders 1 and 2, then divided the scores by the number of puzzles created by the participant. In this way, I determined the absolute creativity level produced by each participant. A participant might generate more puzzles, but it does not necessary mean that the participant is more creative.

Correlations of average creativity ratings between the two graders was 0.97 . Such correlation was statistically significant for the two raters. As a measure of inter-rater reliability, Cronbach’s Alpha was 0.98, which exceeds typical reliability thresholds (Peterson, 1994). Therefore, I have reason to believe that the raters are reasonably consistent and that their average is a reliable measurement of creativity.

\section{Determining Retention Rating}

In the last part of the study, I invited participants to stay for as long as they wished. Since each puzzle was timed, I could use the number of puzzles created by the individual to determine 
the retention rate. On average, participants created 9.75 puzzles (29.25 minutes) before they

abandoned the task. However, the link between the intangible reward and retention was 0.01 .

Such correlation is statistically insignificant, suggesting there was nearly no relationship between

the two variables.

\section{DATA ANALYSIS \& RESULTS}

\section{Data Overview}

Out of the 57 participants, there were 31 women and 26 men. The participants’ age ranged from 18 to 59, with a mean age of 29.96 years. Means, standard deviations, and correlation of the key variables are reported in Table 1.

Table 1: Overall Mean, Standard Deviation, and Correlations

1. Intangible Reward

2. Creativity

3. Retention

4. Intrinsic Motivation

5. Extrinsic Motivation

6. Challenge(IM) ${ }^{1}$

7. Enjoyment(IM) ${ }^{1}$

8. Compensation(EM) ${ }^{1}$

9. Outwards(EM) ${ }^{1}$

10. Age

11. Gender

\begin{tabular}{|c|c|c|c|c|c|c|c|c|c|c|}
\hline $\mathrm{M}(\mathrm{SD})$ & 1 & 2 & 3 & 4 & 5 & 6 & 7 & 8 & 9 & 10 \\
\hline $\mathrm{n} / \mathrm{a}(\mathrm{n} / \mathrm{a})$ & 1 & & & & & & & & & \\
\hline $2.91(0.92)$ & 0.14 & 1 & & & & & & & & \\
\hline $9.75(4.88)$ & -0.05 & $0.28^{*}$ & 1 & & & & & & & \\
\hline $3.04(0.35)$ & $-0.25 *$ & $-0.34 * *$ & -0.06 & 1 & & & & & & \\
\hline $2.57(0.36)$ & $0.23^{*}$ & 0.14 & -0.05 & $-0.25^{*}$ & 1 & & & & & \\
\hline $3.19(0.36)$ & -0.16 & $-0.31 * *$ & -0.04 & $0.85^{* *}$ & -0.14 & 1 & & & & \\
\hline $2.57(0.38)$ & $0.23^{*}$ & 0.14 & -0.05 & $-0.25^{*}$ & $1.00 * *$ & -0.14 & 1 & & & \\
\hline $2.43(0.47)$ & $0.22 *$ & 0.11 & -0.01 & -0.16 & $0.93 * *$ & -0.04 & $0.93 * *$ & 1 & & \\
\hline $2.82(0.58)$ & $-0.25^{*}$ & $-0.23^{*}$ & -0.06 & $0.76 * *$ & $-0.28 *$ & $0.30 * *$ & $-0.28 *$ & $-0.24 *$ & 1 & \\
\hline 28.97 (9.05) & 0.03 & $-0.25^{*}$ & 0.08 & 0.12 & 0.01 & 0.03 & 0.01 & 0.06 & 0.17 & 1 \\
\hline $\mathrm{n} / \mathrm{a}(\mathrm{n} / \mathrm{a})$ & $\mathrm{n} / \mathrm{a}$ & $-0.37 * *$ & 0.03 & $0.31 * *$ & -0.16 & 0.16 & -0.16 & -0.10 & $0.36 * *$ & $0.27^{*}$ \\
\hline
\end{tabular}

* Correlation is significant at the 0.05 level (1-tailed)

** Correlation is significant at the 0.01 level (1-tailed)

\section{Hypothesis 1 \& 2}

Hypotheses 1 and 2 measure the relationship between the two motivators and creativity.

The results suggest that intrinsic motivators are negatively correlated to creativity in a significant way $\beta=-0.37, t=2.98, \mathrm{p}<0.01$. This finding opposes what I have learned in the literature; several

\footnotetext{
${ }^{1}$ The Work Preference Inventory (WPI) instrument measures primary factors (intrinsic and extrinsic motivations) and secondary factors (challenge, enjoyment, compensation, and outwards). The secondary factors are intended to serve as more fine-grained breakdowns of the elements of intrinsic and extrinsic motivation. The two intrinsic sub-factors are interpretable as challenge and enjoyment. The two extrinsic sub-factors are interpretable as compensation and outward (oriented toward the recognition and the dictates of others) (Amabile, 1994).
} 
researchers have shown that individuals’ interest in a task increases their intrinsic motivation. Therefore, when they perceive the task as interesting and challenging, they will be creative (Deci, 1972; Shalley, Gilson, \& Blum, 2000).

With respect to extrinsic motivation, as suggested in the literature, there was a positive relationship between extrinsic motivation and creativity but the relationship was not significant $(\beta=0.17, t=1.30, p=0.20)$. This result is contradictory to some research findings, where additional reward diminishes the ability of being creative (Miller, Hom \& Gomez-Mejia, 2001). However, it is important to note that their research was referring to high performers. The average creativity score in the study was 2.9 out of 5.0. It was not relatively high, given the goal was 4.5 out of 5.0. Besides, the standard deviation was high (0.92) suggesting there were not many high performers in the study to confirm that claim was valid. In fact, as per the results, out of the 57 individuals, only 2 individuals exceeded the goal of 4.5 out of 5.0.

Based on these results, hypotheses 1 and 2 are not supported.

\section{Hypothesis 3 \& 4}

Hypothesis 3 and 4 concern the relationship between the two motivators and retention. The result suggests that there is no significant relationship between these variables. Moreover, the regression analysis suggests that the two motivators are not significantly related to retention. The p-value for the intrinsic motivator was 0.87 and the p-value for the extrinsic motivator was 0.91 .

In fact, the result suggests if there is a relationship between these variables, it would be in the opposite direction, though this is not significant. Given this hypothesis is not well supported, I suspect other factors such as job satisfaction may be a better contributor to retention (see discussion section for further discussion on this issue). 
Based on the results, hypotheses $3 \& 4$ are not supported.

\section{Hypothesis 5, 6, 7, \& 8}

A Baron and Kenny (1986) moderation analysis model is conducted to assess if the intangible reward moderates the relationship between the two motivators, creativity, and retention.

To examine for a possible moderation effect, a multiple linear regression is conducted. The independent variables of the regression are intrinsic motivation, intangible reward, and the interaction between independent variable and moderator. To avoid unnecessary multicollinearity, centering the variables using the means is necessary. This is not a requirement for the dependent variable (i.e. creativity). But for the independent variables of intrinsic motivation and intangible

reward. The interaction is created by multiplying independent variable (intrinsic motivation) and moderator (intangible reward). After that, I run a regression putting all of the new variables together to test for moderation. The R-squared is a percentage of the response variable variation that is explained by a linear model. The R-squared after the introduction of the interaction variable has slightly changed from $14.7 \%$ to $15 \%$. The result is not strong enough to suggest the moderation effect of intangible reward. Furthermore, the regression results show that intangible reward strengthens the relationship between intrinsic motivation and creativity but this effect is not significant $(\beta=0.06, t=0.49, p=0.63$, see Fig 1.6). The moderator (intangible reward) is not statistically significant as the p-value is 0.63 . As shown in Fig 1.7, the positive moderator is not significant either. Therefore, the conclusion is that the intangible reward does not significantly strengthen the relationship between intrinsic motivation and creativity thus hypothesis 5 is not supported.

For hypothesis 6, where I assess if the intangible reward moderates the relationship between extrinsic motivation and creativity, I duplicate the steps indicated before. To create an 
interaction, I multiply the extrinsic motivation variable and the intangible reward variable. The R-squared jumps from 3\% to $9.5 \%$. This result suggests that the moderator (intangible reward) is a better explanation than a simple regression. However, the moderation effect is not at an optimal result. Furthermore, the regression results show that an intangible reward strengthens the relationship between extrinsic motivation and creativity $\beta=0.22$, $t=1.64, \mathrm{p}<0.1$ (see Fig 1.8 ). The p-value indicates that the relationship is marginally significant. As shown in Fig1.9, the positive moderator reaction is somewhat strong. However, it is important to note that this relationship is the opposite of what I predicted. There are several reasons to explain this, which I discuss in the next section. Based on the result, the intangible reward has an opposite effect on extrinsic motivation and creativity; therefore, hypothesis 6 is rejected.

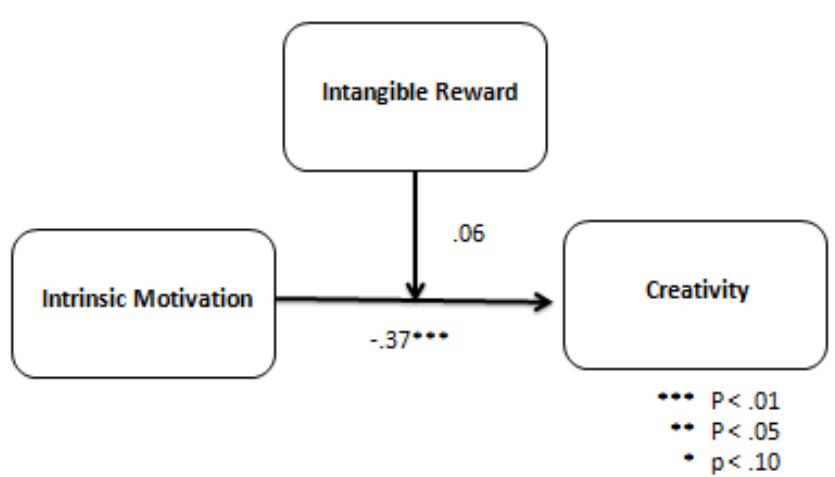

Figure 1.6: Moderation role of intangible reward on intrinsic motivation and creativity

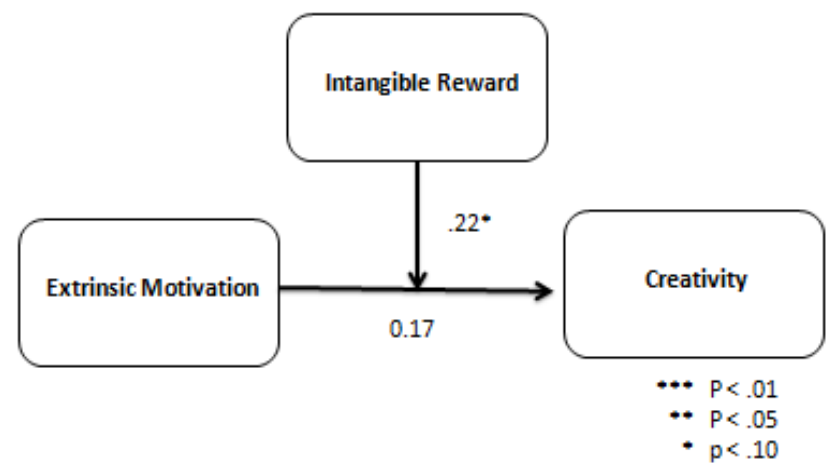

Figure 1.8: Moderation role of intangible reward on extrinsic motivation and creativity

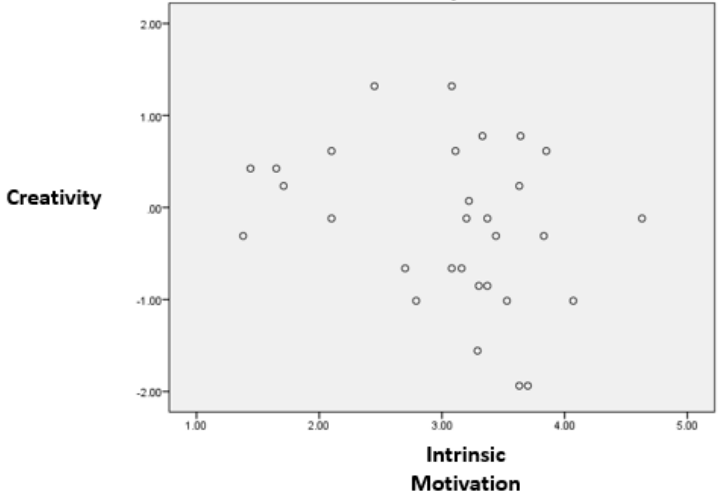

Figure 1.7: Scatter-plot for the moderation role of intangible reward on intrinsic motivation and creativity

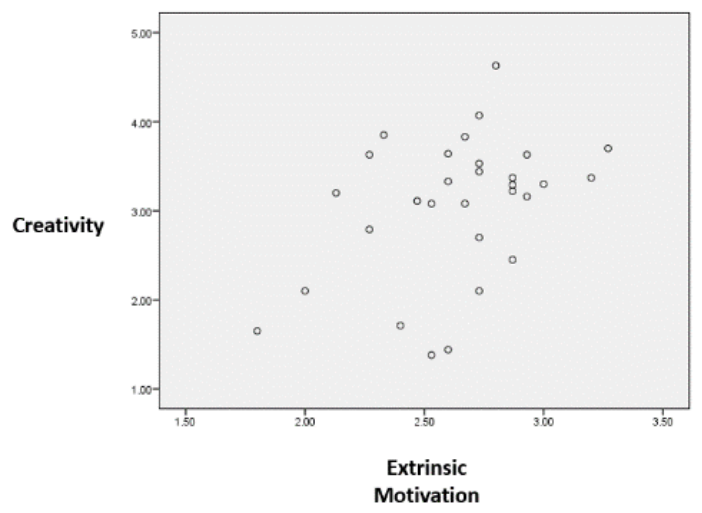

Figure 1.9: Scatter-plot for the moderation role of intangible reward on extrinsic motivation and creativity 
For hypothesis 7, I repeat the steps as indicated for the previous hypotheses. I standardize the independent variables (intangible reward and intrinsic motivation), and then I run a regression putting all of the new variables together to test for moderation. The R-squared changes from $0.1 \%$ to $0.2 \%$. This result does not suggest that intangible reward is a variable that contributes to retention. Furthermore, the regression results show that an intangible reward does not strengthen or weaken the relationship between intrinsic motivation and retention. In fact, it shows that an intangible reward does not play a moderation role on intrinsic motivation and retention, $\beta=-0.04, t=-0.30, p=0.76$ (see Fig. 1.10). As shown in Fig 1.11, there is no moderation reaction. Therefore, I conclude that the intangible reward does not have any impact on intrinsic motivation and retention. As a result, hypothesis 7 is not supported.

For hypothesis 8, I multiply the extrinsic motivation variable and the intangible reward variable to create an interaction. The R-squared increases from $0 \%$ to $0.7 \%$. Although the intangible reward offers a better explanation for the relationship between extrinsic motivation and retention, the relationship is not strong. Furthermore, the regression results show that an intangible reward weakens the relationship between extrinsic motivation and retention $\beta=0.08$, $\mathrm{t}=-0.59, \mathrm{p}=0.56$ (see Fig 1.12 ). This relationship is not statically significant, as the $\mathrm{p}-\mathrm{value}=0.56$. As shown in Fig 1.13, the moderator reaction is weak. Although results show that an intangible reward positively moderates the relationship between extrinsic motivation and retention, this relationship is not significant. As a result, hypothesis 8 is rejected. 


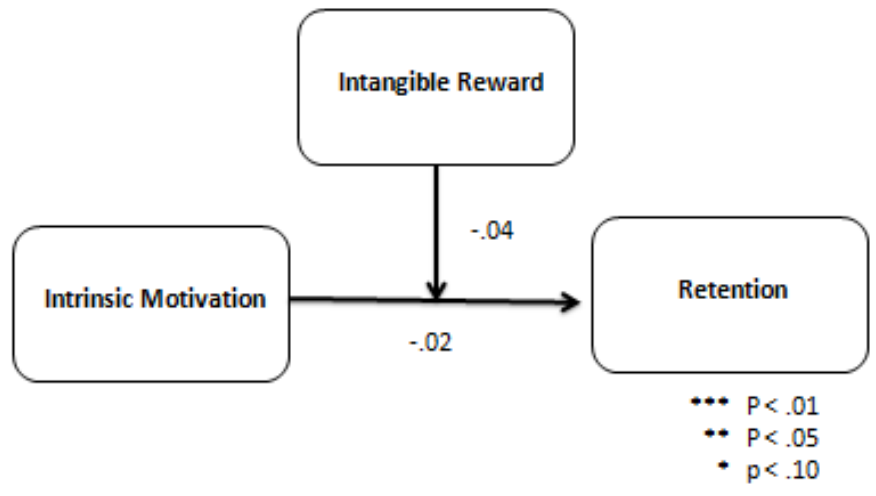

Figure 1.10: Moderation role of intangible reward on intrinsic motivation and retention

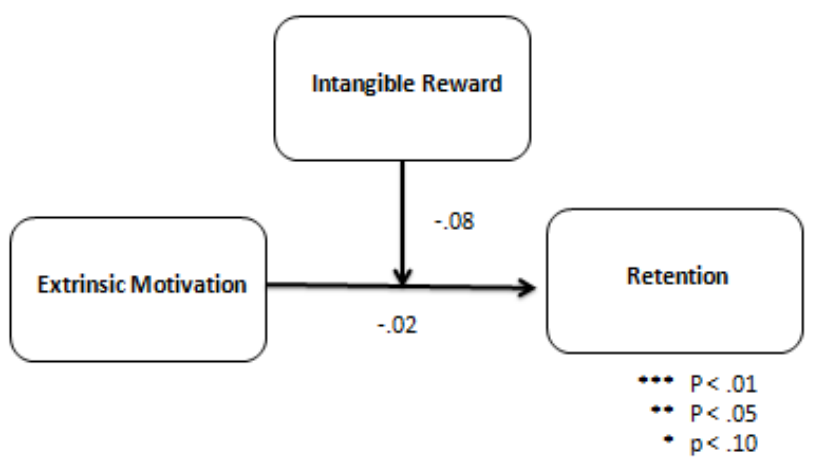

Figure 1.12: Moderation role of intangible reward on extrinsic motivation and creativity

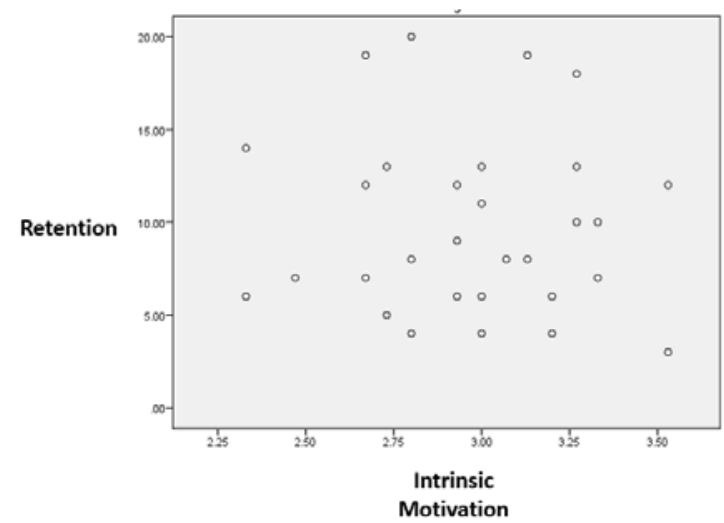

Figure 1.11: Scatter-plot for the moderation role of intangible reward on intrinsic motivation and retention

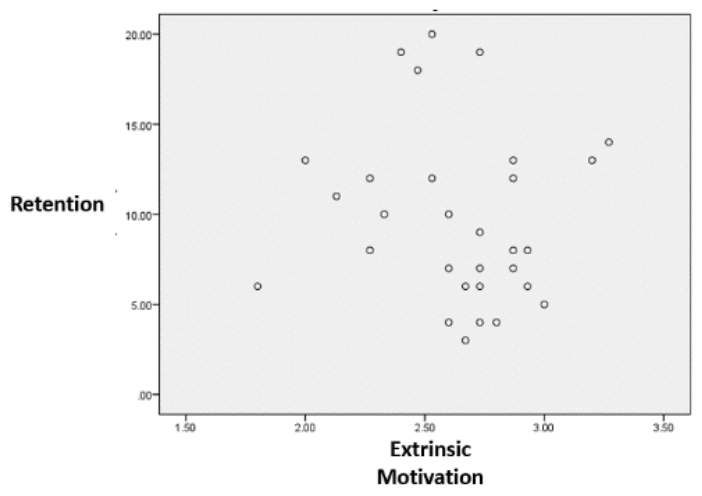

Figure 1.13: Scatter-plot for the moderation role of intangible reward on extrinsic motivation and retention

\section{STUDY 1: DISCUSSION \& IMPLICATIONS}

Although research has shown that intrinsic motivation is a better predictor of creative performance (Deci, 1972), the results of this study point to the contrary. There is a strong negative correlation between intrinsic motivation and creativity. When individuals were intrinsically motivated, they were not as creative as those in the control treatment. A possible explanation is that these individuals perceived the intangible reward as a tangible reward, which would diminish their creativity level, as suggested in several studies (Amabile, 1996; Prabhu, 
Sutton \& Sauser, 2008). CET theory suggests the same principle: individuals may have seen the feedback as an external reward, enhancing their extrinsic motivation (Deci, Koestner, \& Ryan, 2001). In fact, the results support this notion. The intangible reward did not strengthen the relationship between the extrinsic motivator and creativity. Although this effect was only marginally significant, I believe that if I were to collect more samples, the p-value would become significant.

In addition, in accordance with the literature, there are multiple ways to increase intrinsic motivation, such as when individuals see the task as interesting or challenging (Gagne \& Forest, 2008). The participants in this study may not have enjoyed the task as much as I had hoped, which could be an experimental design error, as discussed in the next section.

As suggested in the literature, when an intangible reward is present, it may weaken the relationship between extrinsic motivation and creativity. However, the data suggests the opposite view. Expectancy theory may explain this finding. Expectancy theory suggests that extrinsic rewards can lead to a better performance if the individual believes the goal is attainable and that the reward is attractive. There are three important parts to expectancy theory: expectancy, instrumentality, and valence (Vroom, 1964). Expectancy refers to an individual's subjective view that they can achieve a particular level of performance on a task. Instrumentality refers to the subjective likelihood that the attainment of the outcome will lead to attractive consequences. Valence refers to the value the individual places upon the expected outcome. Therefore, when a self-identified creative individual expects an attractive reward for a certain performance (i.e., the assigned goal), the individual will have higher motivation and perform better.

The results suggest that retention has a positive association with creativity. The longer the individual stays, the better his/her creativity becomes. Shalley, Gibson, and Blum (2000) confirm 
this notion, suggesting that a task that is high on required creativity is also relatively high on complexity and autonomy, which will increase the individual's task satisfaction and lessen his/her intention to leave their job. However, when accounting for the secondary factors, the results suggest that when the individuals perceive the task as challenging and enjoyable, their creativity level is disappointing. This finding presents an opposing view to Deci (1972), who suggests that when a task is perceived as interesting, the individual has the freedom to be creative and thus perform better. A possible explanation is that individuals did not see the experiment as challenging or enjoyable. Unfortunately, I am unable to confirm this assumption, as no individual feedback was collected after the experiment was concluded.

I also find a weak negative correlation between the two motivators and retention. This finding is the opposite of what I expected. A possible explanation may be that the experiment was not challenging or enjoyable enough to stimulate intrinsic motivation, or that the individuals perceived the intangible reward as a tangible reward, undermining intrinsic motivation, or that the tangible reward condition was not strong enough to strengthen extrinsic motivation. Nonetheless, it is difficult to identify the reason due to the design of the experiment.

\section{STUDY 1: LIMITATIONS}

There are a few limitations in this study. First, the design of the experiment is far from perfect. For example, Hennessy \& Amabile (1998) suggest that social and environmental factors play major roles in an individual's creative performance. People will be more creative when they perceive the task as interesting. However, I did not incorporate this variable in the study, therefore I do not have data about how the individuals felt about the task. Similarly, Deci (1972) suggests that when individuals perceive the task as interesting, they will stay longer. The fact that I did not perform a post-experiment survey prevented me from finding out the true reasons 
for why the individual decided to abandon the task. In addition, there is a potential problem in the sequence of the experiment. I distributed the survey, designed to measure individuals’ motivation orientation, after the practice period and before the treatments were given. This sequence rendered me unable to make observations on the effect of the intangible reward on the two motivators. If the survey had been given to the individual after the experiment, I would have been able to draw a connection between the intangible reward and the two motivators. In addition, I did not conduct a manipulation check for tangible or intangible reward in the study. A manipulation check can help to rule out reasons that a manipulation may have failed to influence a dependent variable. Therefore, it is difficult to conclude that the manipulations in the study were effective.

Second, the treatments (tangible reward and intangible reward) provided in the study were non-distinctive and weak. As a result, the treatment results were mixed. Either the tangible reward was not attractive enough to promote extrinsic motivation, or individuals perceived the intangible reward as a tangible reward, diminishing intrinsic motivation. From the study, the effect of an intangible reward to the relationship of extrinsic motivation and creativity was inverse to literature perspectives. Deci, Koestner, and Ryan (2001) found that it is possible that individuals might perceive the intangible reward as a tangible reward. Therefore, it was possible that participants in the study perceived positive feedback as a tangible reward. Unfortunately, it was unable to confirm this assumption. The treatment plan should have been clear to allow for a clear result. For example, individuals who are given the intangible reward treatment would receive nothing, as the task itself should be interesting and challenging enough to promote intrinsic motivation (Deci 1972). Individuals who were given the tangible reward treatment would receive cash, promoting extrinsic motivation in accordance with expectancy theory. 
Moreover, the feedback that was used in the experiment was considered an example of controlling feedback. As suggested in the literature, I avoided the word "should" in the feedback, but individuals may still have perceived my feedback as controlling feedback. According to the literature, controlling feedback leads to less intrinsic motivation (Ryan, 1982; Pittman, Davey, Alafat, Wetherill, \& Kramer, 1980). I should have given the individuals information feedback that only contains the result and a comment about how the individual performed in the practice round.

Third, due to time constraints, I conducted the experiment in a classroom setting, which may have led to contamination. For most of the sessions, there were at least two individuals. Although they were blinded to each other's treatment, they were able to see each other. Therefore, when a person leaves the experiment, the other person tends to leave the experiment within the next five to ten minutes. That was the main reason why there were no significant results between the two treatments. Moreover, I conducted the experiment individually in some sessions. The individual may have felt obligated to end the experiment, because they felt embarrassed for prolonging the experiment. Although I did not collect the reasons why an individual would abandon the experiment on paper, I verbally asked a few participants. Some of them left the experiment because of personal obligations such as meetings and doctor's appointments. Others claimed they were getting hungry or ran out of ideas. None of them commented on the treatment given, which leads me to believe that the treatments themselves were not significant enough to entice the individual.

Fourth, it is interesting to note the sample of the study. Although, the age (mean for women was 28.39 and mean for men was 31.85) and treatment plan (women: tangible 14 \& intangible 17; men: tangible $13 \&$ intangible 13) were fairly distributed between genders, the 
jobs that the participants held were significantly different. In the study, female participants were mainly employed in administrative roles, such as business administration assistant and coordinator, whereas male participants were in more professional roles such as engineer, innovation leader, and marketing developer. Differences in professional background may present a limitation to the study when measuring creativity and retention, as one cannot generalize findings.

In addition, during the recruitment process I chose to post flyers on campus and invited individuals on the street to participate in the study. The poster said that an individual who participated in the study would earn up to \$15. I used similar wording when I recruited individuals on the street. By disclosing the reward in advance, I risked contaminating the data, as individuals may have already expected a tangible rewarded of up to $\$ 15$, which by nature becomes an extrinsic reward. Therefore, the treatments given in the study may not have been strong enough to alter the individual's behaviour.

Finally, due to the budget constraints, I collected only 67 samples. Based on the central limit theorem (Andersen, Borgan, Gill, \& Keiding, 2012), I should have collected samples from at least 30 people per treatment. Had I collected more samples, the results may have been different.

STUDY 2: THE RELATIONSHIP BETWEEN TANGIBLE REWARD, MOTIVATIONS, AND CREATIVITY

In Study 1, I learned that there is a negative relationship between intangible reward and creativity. One of the limitations of Study 1 is that participants may have perceived the intangible reward as a tangible reward (see limitations section). Therefore, it is possible that there is a positive relationship between tangible reward and creativity. Thus, a primary objective of study 2 
is to examine this phenomenon. In this study, I explore the relationship between tangible reward, motivation, and creativity. I also test the mediation effect of intrinsic motivation on creativity.

\section{STUDY 2: THEORETICAL FRAMEWORK \& HYPOTHESES}

As discussed in the literature section, Amabile and her colleagues do not see the value in rewards, as they shift the individual's focus from the assigned task to the reward. They suggest that an individual should have relevant skills in a given field in order to perform at a required level (Amabile, 1983; Amabile \& Hennessey, 1988). However, in a later study, Amabile explicitly acknowledges that extrinsic rewards can have positive effects on creativity, pointing out that: 1) extrinsic rewards do not necessarily undermine creativity and may actually enhance creativity; 2) the positive effects are most likely to occur when intrinsic motivation is already

high; and 3) a positive effect may come via positive effects on perceived competence (Hennessey \& Amabile, 2010).

Similarly, Eisenberger and Rhoades (2001) argue that expected reward might improve creative task performance by enhancing perceived self-determination. They also find that an individual's intrinsic interest in the task mediates a positive relationship between expected reward for high performance and creativity. Based on these observations, I have created the following model and hypotheses to test in Study 2.

\section{H9 - There is a positive relationship between tangible reward and creativity.}




\section{H10 - Intrinsic motivation fully mediates the relationship between tangible reward and creativity.}

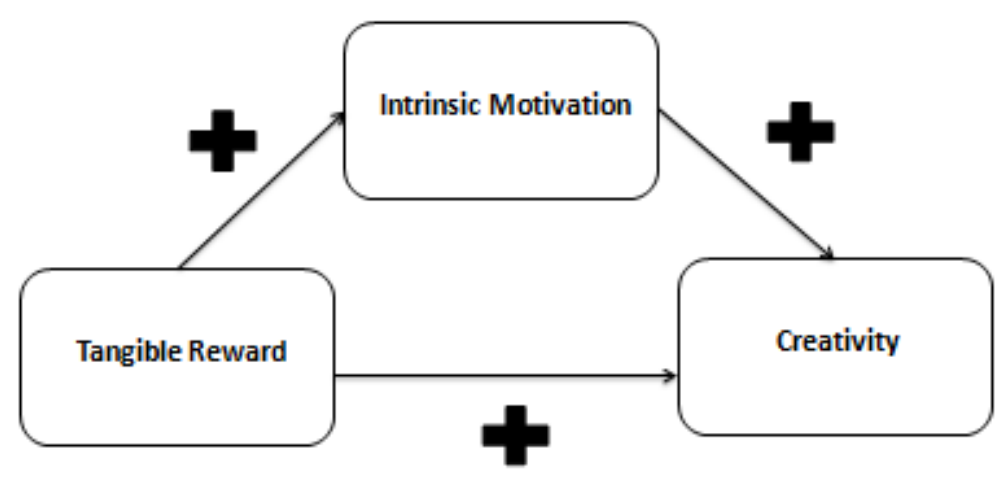

Figure 1.5: Mediating Role of intrinsic motivation on tangible reward and creativity

\section{STUDY 2: METHODOLOGY}

Creativity is a multi-dimensional concept. Following Sternberg (1999), I operationalize and examine two types of creativity: “closed” and "open” creativity. In "closed” creativity, there is a specific and delineated goal, for example, finding a way to decrease the size of a computer or developing a new drug for a specific purpose. The puzzle task adopted in Study 1 is another example of closed creativity. Although, Kachelmeier, Reichert, \& Williamson (2008) consider the puzzle task to be an example of “open” creativity, I argue that it is “closed” creativity, because the examples given in the instructions were thorough, limiting the participant's ability to think outside the box. Most of the participants simply changed the wording of an existing pattern. In addition, the graders were asked to provide a grade based on originality, innovation, and cleverness. However, I did not provide a definition of originality, innovation, and cleverness. Judging by the rebus puzzles the participants submitted, none of them created a new type of 
puzzle. Therefore, it is presumable that the graders defined originality as a clever creation instead of a new idea. On the other hand, "open” creativity represents unfettered thinking outside the box; there is no obvious underlying ex-ante goal or direction. In Study 2, I use the "create an app" task to represent an "open” creativity type.

This study uses a single dimension: the absence and presence of monetary incentives. The study has two treatments: Treatment 1 (control): participants are asked to design an app and are encouraged to be as creative as they can be without any treatment condition; Treatment 2 (monetary gift not tied to relative performance): participants are asked to design an app and are encouraged to be as creative as they can be. Moreover, they are told that they will receive a token of appreciation of $\$ 5$ cash for their effort. The instructions for both treatments can be found in Appendix C.

Participants are all undergraduate students recruited by SONA, a research participant pool system organized by Ryerson University. They were invited to take part in one of the five sessions. In a classroom setting, participants were given 30 minutes to design an app with a description or illustration to discuss what the app does. Afterwards, they were asked to complete a short survey that consisted of some demographic questions and how they felt about the task.

I have adopted the scale of situational intrinsic and extrinsic motivation from Guay, Vallerand, and Blanchard (2000). The WPI scale used in Study 1 measures the general intrinsic and extrinsic motivation of an individual. However, motivation may be contextualized for a given task. Therefore, I contend that the situational motivations scale is more appropriate for measuring one motivation in a task. All items are measured on 7-point Likert scales ranging from 1 (Not at all for this reason) to 7 (Exactly for this reason). There are four items to measure 
intrinsic motivation $(\alpha=.89)$. Sample items of intrinsic motivation are "Because I think that this activity is interesting” and "Because I think that this activity is pleasant."

The scale also measures other factors: identified regulation ( $\alpha=.69)$, external regulation ( $\alpha=.83$ ), and amotivation $(\alpha=.80)$. Identified regulation occurs when a behaviour is valued and perceived as being chosen by oneself. However, this is considered extrinsic motivation, as one is motivated to perform a task for an incremental reason. External regulation occurs when behaviour is regulated by rewards or in order to avoid negative consequences. Amotivation is similar to de-motivation, where the individual does not have a sense of purpose and is not motivated by a reward.

\section{The Measurement of Creativity Level}

Similar to Study 1, I recruited two graders who were blind to the treatment conditions. The rating scale was on a 1 (not creative at all) to 7 (extremely creative) scale. The graders received the same common instructions that the participants read in the experiment but without the last part about treatment condition. They were asked to read the write-ups or drawing of an App design idea on a scale of 1 to 7 described above. It is important to note that the raters were asked to only rate the quality/creativity of the app and were not asked to judge feasibility at all.

The correlation between the two graders was 0.62. The Cronbach’s Alpha score was 0.75, which is within the acceptable range (Peterson, 1994). Therefore, I have reason to believe that the raters are reasonably consistent such that their average is reliable as a measurement for creativity. To calculate the creativity score, I took the average score of grader 1 and grader 2.

\section{DATA ANALYSIS \& RESULTS}

\section{Data Overview}


Of the 43 participants, there were 30 women and 13 men. The participants' ages ranged from 17 to 28, with a mean age of 20.77 years. Means, standard deviations, and correlation of the key variables are reported in Table 2 .

Table 2: Overall Mean, Standard Deviation, and Correlations

1. Tangible Reward

2. Creativity

3. Intrinsic Motivation

4. Identified Regulation

5. External regulation

6. Amotivation

7. Age

8. Gender

$\begin{array}{cc}\mathrm{M}(\mathrm{SD}) & 1 \\ \mathrm{n} / \mathrm{a}(\mathrm{n} / \mathrm{a}) & 1 \\ 4.64(1.63) & 0.35^{*} \\ 5.33(1.30) & 0.07 \\ 4.83(1.34) & -0.01 \\ 3.33(1.46) & -0.04 \\ 2.40(1.29) & -0.17 \\ 21.03(2.80) & 0.24 \\ \mathrm{n} / \mathrm{a}(\mathrm{n} / \mathrm{a}) & -0.24\end{array}$

2
1
$0.24^{*}$
-0.02
-0.19
$-0.27^{*}$
0.04
0.15

3

$4 \quad 5$

6

7

8

Hypothesis 9

Hypothesis 9 measures the relationship between tangible reward and creativity. The results suggest that tangible reward is positively correlated to creativity in a significant way $(\beta=$ 0.35, $\mathrm{t}=2.36, \mathrm{p}<0.01)$. This finding is aligned with what I have learned in the literature; several researchers have shown that individuals' interest in a task increases the their intrinsic motivation (Deci, 1972; Shalley, Gilson, \& Blum, 2000). This suggests that the task, creating an App, is more interesting and challenging than a rebus puzzle. Based on the results, hypothesis 1 is supported.

\section{Hypothesis 10}

I follow Baron \& Kenny (1986) to examine the mediator (intrinsic motivation) effect on creativity. The first step is to examine the relationship between the independent variable (tangible reward) and the dependent variable (creativity). I then examine the relationship between the independent variable (tangible reward) and the mediator (intrinsic motivator). Regression results show that the relationship between tangible reward and intrinsic motivation is 
not significant $(\beta=0.07, \mathrm{t}=0.47, \mathrm{p}=0.64)$. Next, I examine the relationship between the mediator (intrinsic motivator) and the dependent variable (creativity). Regression results show that the influence of intrinsic motivation on creativity is significant $(\beta=0.24 \mathrm{t}=1.97, \mathrm{p}<0.05)$. The last step includes the mediator and the independent variable in the model to examine whether this reduces the effect of the antecedents to non-significance. The mediation analysis reveals that intrinsic motivation does not fully mediate the relationship between the treatments and creativity (see Fig 2.1). When I introduce intrinsic motivation into the model, the relationship between the independent variable (tangible reward) and the dependent variable (creativity) remains significant, $\beta=0.34, \mathrm{t}=2.28, \mathrm{p}<0.05$. Therefore, the second hypothesis is not supported.

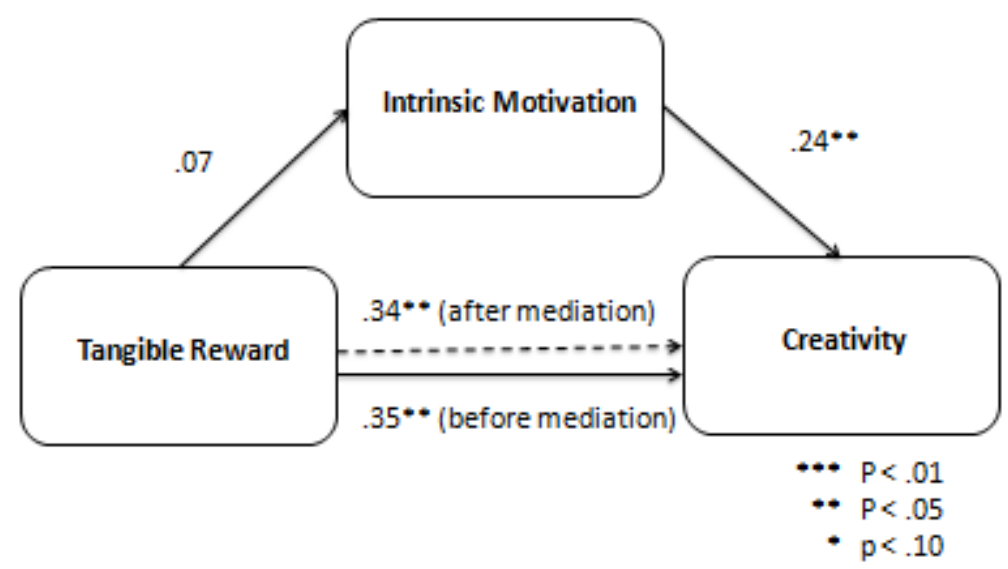

Figure 2.1: Mediating role of intrinsic motivation on creativity

\section{STUDY 2: DISCUSSION \& IMPLICATIONS}

Study 2 confirms findings in several studies that have found that intrinsic motivation is a better predication for creative performance than extrinsic motivation (Deci, 1972). There is a strong positive correlation between intrinsic motivation and creativity. When individuals are intrinsically motivated, they are able to perform creatively. This study also confirms that participants in Study 1 perceived the intangible reward as a tangible reward. There is a positive 
and strong correlation between tangible reward and creativity. However, as Amabile (1996) suggests, tangible rewards tend to diminish an individual's creativity level, as it directs the individual to focus on the reward rather than the task. Study 2 confirms this notion, finding no significant relationship between tangible reward and intrinsic motivation.

From Study 2, we learn that when given a tangible reward, the individual is able to perform creatively. However, this relationship cannot be explained by intrinsic motivation. If it is not intrinsic motivation, could the relationship be explained by the extrinsic motivation? Results from the regression analysis I conducted on the two extrinsic variables (identified regulation and external regulation) from the situational motivational scale. The p-value for identified regulation is 0.97 and the p-value for the external regulation is 0.82 . The results for both variables are nonsignificant. Though both are in the right direction, neither is significant.

To conclude, motivation is not the reason that a tangible reward leads to creativity. There may be other mediating factors that provide a better explanation for this relationship.

\section{STUDY 2: LIMITATIONS}

There are a few limitations in study 2. First of all, the sample size of the study is on the small side and the gender proportion was not quite balanced. First, my sample size per treatment may not be big enough. In the study, I had 21 control treatment and 22 reward treatment. Secondly, the total number of participants was 43 but female participants (30) were twice the size of male participants (13). This may have an impact on the average creative score and general correlations. Based on the central limit theorem (Andersen, Borgan, Gill, \& Keiding, 2012), I should have collected at least 30 people per treatment. If the sample size is not big enough, it is hard to infer any statistical significance between variables. If I had more samples, the result could have been different. Lastly, although the reliability test between the two graders was within the ac- 
ceptable statistical range, the correlation between the two graders was weak (0.62). This means the consistency between the two graders was not robust. With different perspectives of creativity, it could be hard to conclude the definitive outcome. Therefore, an additional grader should be hired to boost the reliability rate.

\section{GENERAL DISCUSSION AND IMPLICATIONS}

The results of my research indicate that a tangible reward does induce creativity and that intrinsic motivation is positively related to creativity. However, the intangible reward does not have a moderation effect on the relationship between intrinsic motivation and creativity. Similarly, intrinsic motivation does not have a mediation effect on the relationship between tangible reward and creativity. Perhaps the main reason why there is no moderation or mediation effects between these variables is because the third variable (i.e., the intangible reward in Study 1 and intrinsic motivation in Study 2) cannot be measured in a single dimension (i.e., a single independent variable leads to a predictive variable). There are multiple independent variables in these studies that I failed to measure; these might have contributed to the predictive variables. For example, Malik, Butt, and Choi (2015) find that tangible reward for creativity positively predicts creative performance only when employees have high creative self-efficacy and regard such rewards as important. In their study, they use a questionnaire to measure the individual's self-efficacy and the importance of a reward to an individual. Both of my studies used two established scales to measure motivations. Although it is a good idea to include a wellrecognized scale, it restricted the number of questions I could include in the study. Therefore, I was unable to measure many important factors, such as the importance of a reward to an individual and self-efficacy. 
Comparing the two studies, Study 2 yielded a different result in terms of the relationship between tangible reward and intrinsic motivation. Study 1 suggests a significant relationship between the two variables, while Study 2 suggests the opposite. It is possible that a type I error occurs in Study 2 or that a type II error occurs in Study 1. A type I error is the incorrect rejection of a true null hypothesis. A type II error is incorrectly retaining a false null hypothesis (i.e., there is a positive relationship between tangible reward and intrinsic motivation). Despite the fact that Study 2 had a small sample size, the correlation and regression results were nowhere near significant. It is very unlikely that a bigger sample would have changed these results. Therefore, I reject the notion that a type I error occurs in Study 2.

On the other hand, it is possible that a type II error occurs in Study 1. As suggested in Deci, Koestner, and Ryan (1999), rewards may significantly undermine intrinsic motivation. Amabile (1983) also finds that rewards create distractions that prevent an individual from achieving an assigned goal. Why, then, is the statistical power so high in Study 1 that it gives an illusion that a tangible reward might give way to intrinsic motivation? This error could have been caused by the sample size. The sample size in Study 1 is slightly bigger than that of Study 2 . However, it might not be big enough to determine the true relationship between the two variables. Calculating the sample size during the experiment's design stages will help to reduce these types of errors in the future.

The research method I chose for both studies might have influenced the overall results. In both studies, I used the experimental method to observe the causation effect between observed variables. This method has been adopted by numerous scholars, such as Choi (2004), Cadsby, Song, and Tapon (2007), and Kachelmeier and Williamson (2010) to explore the subject of creativity. Experimental methods are a type of quantitative method. According to Blaikie (2010), 
an advantage of conducting an experiment is that the high degree of control allows researchers to control their variables, and results can span across the field of research. However, there are also drawbacks to experiments. For example, an experimental study is subject to human errors. Experimental studies require extensive time. Due to the time length of the study period, any form of error may have occurred during the data collection phase of my study. These errors can be systematic (error with the experiment) or human errors (e.g., revealing who the control group is when conducting the experiment in a classroom setting). These errors can destroy the validity of the experiment and affect the results.

In addition, if I had chosen a different quantitative method, such as online survey or questionnaire, I might have seen different results. Advantages of a survey method approach include, but are not limited to, the broad range of data that can be collected, the fact that they are relatively easy to administer, and the fact that numerous questions can be asked about a subject (Blaikie, 2010). Since many scholars (Griffeth, Hom, \& Gaertner, 2000; Hennessey \& Amabile, 1998; Malik, Butt, \& Choi, 2015) suggest that multiple factors contribute to creativity, it might be a better idea to conduct a survey in order to observe all possible factors that contribute to creativity. However, it is important to note that there are some disadvantages to survey methods. For example, surveys may use an ambiguous rating system that may prevent the participant from telling the truth, and surveys do not provide the participant with the ability to clarify answers. To overcome these challenges, I need to provide a defined scale and leave space on the survey for participants to express their thoughts.

Many employers are now considering creativity as a core competency. These employers understand that individual creative thinking is what separate them from their competitors. Creativity is a competitive advantage because it is the main substance of business creation. iTunes is 
one example of creative thinking. Apple Inc. invented a new way for music lovers to enjoy music. In return, Apple experienced substantial growths in business. Another example of creative thinking is Netflix. Netflix started as a DVD mail subscription business and it is now the world's leading internet entertainment service with over 109 million members in over 190 countries (McCord, 2014). Netflix created a new way for people to enjoy TV shows and movies. These examples are evident that creativity adds value to the business. Therefore, employers should start encouraging creative work in their workplace. This study suggests that one way to foster creativity in a workplace is to implement pay-for-creativity that focuses on rewarding employees for creative thinking. There are several steps to this. The very first step is to identify project objectives. Creativity must be one of the main objectives. Once the objectives are identified, the second step is to communicate these objectives with employees. As noted in the study, "open-end" creative task is better than "closed-end" creative task because the former allows "truly" creative thinking. In the study, I used puzzle task and App creation task to test for creativity. The lack of significant results in study 1 could have been a function of the fact that creativity was not really being assessed through the puzzles since so many examples/instructions were provided. The participants were given the autonomy to create any puzzle they wished, but were not truly creative in that they were constrained by the specific task they had to perform. On the other hand, in study 2, there was less instructions and no guidelines as to how participants should create an app. This type of task could possibly provide a flexibility for the individuals to think creatively. Therefore, it is important not to set the rules too tight as it might restrict individual creative thinking. The last step is to tie the performance with a reward. This study suggests that a tangible reward/intangible reward will yield similar results only when the individual perceives intangible 
rewards as tangible rewards. Therefore, employers should either use a tangible reward or combination of both rewards.

Retention remains the biggest challenge in the workplace as suggested by PayScale. This study shows that creativity is somewhat associated with retention. Therefore, presumably, when an employer introduces more creativity-related projects, it might help with the turnover condition. Moreover, this study suggests that tangible reward might lead to retention. In study 1 , I used a tangible reward versus an intangible reward to measure retention. There was a small difference between the two treatments. Individuals who were in the tangible reward treatment created slightly more puzzles than individuals who were in the intangible reward treatment. Therefore, monetary reward might be a solution to retention. Furthermore, the value of the monetary reward (i.e. the amount of the incentive) might further incentivize employees to stay longer. At the beginning of study 1, all participants were advised that they will receive $\$ 15$ cash as a token of appreciation except for those individuals who received the tangible condition during the experiment. This group of individuals was advised that they could potentially make additional dollars if they meet the assigned requirement. The results suggest that individuals who received a tangible reward treatment stay the longest. Therefore, it is evident that the value of a monetary reward might have an impact on retention. Unfortunately, the impact of a tangible reward is not tested in the study.

Apart from the main takeaway, there are a few implications from the two studies. First, this study shows that tangible rewards are positively related to creativity. It suggests that tangible rewards, such as compensation and benefits, might direct an individual's performance to achieve an assigned goal. Therefore, employers should consider using tangible rewards as incentives when creativity is the measurable outcome. According to this study and the literature, an intangi- 
ble reward (i.e. positive feedback) is equally effective when the employee sees the reward as a tangible reward (Deci, Koestner \& Ryan, 2001).

Second, the key to providing a reward to an employee is timing. This study suggests that the best time to announce the reward is before the assignment begins. By advising employees of the reward before the task begins, an individual can evaluate his/her own ability based on the reward value. According to the expectancy theory, when an individual is extrinsically attracted to the reward and the individual is able to attain the goal, then the individual will perform as assigned (Vroom, 1964).

Third, for creativity tasks it is best to provide the individual with few instructions or guidelines. In Study 1, I provided participants with many examples. This is considered a closed type creativity activity, and it only allowed the participant to generate ideas within the restricted boundary. However, when an open type creativity activity was introduced in Study 2, participants were able to be creative. This observation aligns with the CET theory, which proposes that intrinsic motivation is triggered by the freedom of a task. Therefore, when freedom is given to the individual, he/she is able to perform creatively (Rhoades \& Eisenberger, 2001; Eisenberger \& Aselage, 2009; Deci, Koestner, \& Ryan, 2001).

Lastly, in Study 1 I examine the relationship between rewards, motivations, and retention. Although I did not include retention in Study 2, I have learned that retention is indirectly related to creativity. The results suggest that a year of employment is positively correlated with creative performance (i.e., the longer the employee stays, the more creative they are). Therefore, in order to encourage retention, employers should consider adding outlets for freedom and creativity into all positions (Deci, 1972). Indeed, a lot of companies (e.g., 3M, Google, and Hewlett-Packard) are now providing their employees with a 15\% program. These employers provide an opportu- 
nity for employees to use $15 \%$ of their work time to explore their own projects. When employees feel challenged and valued, they are presumably less likely to leave the company.

\section{FUTURE RESEARCH}

This study identifies important relationships between tangible rewards, intrinsic motivation, and creativity. However, there is much more to discover in the field of creativity. Future studies should investigate the relationship between tangible rewards and creativity, as there are mixed findings in the literature. Different tangible rewards may have different effects on creativity. It would be interesting to conduct a field study to examine the impact of different types of tangible rewards on creativity. In addition, post experiment measurement should also be included in the future experimental studies. The questionnaire will allow the experimenter to measure the effectiveness of the experiment. Some of the suggested measures could be selfassessed creativity, enjoyment of the task and knowledge/experience with the task. Examples are "I do puzzles for fun in my free time" or "I use a variety of apps daily".

In terms of retention, this study suggested that the amount of a monetary reward might make a difference in retention. From the study, individuals who received a tangible reward stayed longer than individuals who received an intangible reward. It would be interesting to explore the value of the monetary reward to retention.

As discussed, there may be a type II error in Study 1 and a type I error in Study 2. One way to avoid this type of problem is to increase the sample size. Another way to reduce the error is to replicate the experiment in Study 1 with improved distinctive treatments. The conditions given to the participants were not non-distinctive in Study 1, where one group received a tangible reward condition and the other group received an intangible reward condition. When both groups receive a similar treatment (i.e., a reward), it is difficult to see the difference between no reward 
and reward, let alone the possibility that participants see an intangible reward as a tangible reward (Deci 1972). In future studies, a control treatment (i.e., no reward) should be given to the participants, as the results would be more interesting to compare across treatment and nontreatment groups.

Furthermore, future studies should include different constructs, such as demographic, self-efficacy, and individual perspectives on rewards, in an attempt to bridge the gap between creativity and retention. However, it is important to note that these constructs may change depending on the task or the individual experience. Therefore, it is equally important to understand the individual's background, such as the individual's education and his/her occupation.

Lastly, I used experiments in this study. As discussed, some of the drawbacks associated with experiments are time commitment and the potential for human error during the experiment. Further studies could replicate the experiment but conduct the study in a more isolated environment. Although it would be time consuming, the results may be different if the experiment were to be conducted on an individual level (i.e., one-on-one) to avoid exposure to peer influence. Alternatively, it may be interesting to measure motivation, rewards, creativity, and retention using a quantitative method, such as an online survey, to acquire additional insights.

\section{CONCLUSION}

This study examines the relationship between rewards, motivation, creativity, and retention. While motivation factors may not fully give way to creative performance and retention, I find that tangible rewards and open-ended performance objectives are key to encouraging creative thinking. This is an important finding for creativity studies. To my knowledge, there is yet to be a study that focuses on the relationship between motivation, creativity, and retention. 
This study has attempted to close the gap. Furthermore, the traditional notion that assumes that professionals are motivated extrinsically, intrinsically, or a combination of both to induce creative thinking may be accurate. From the literature, I learned that an individual's creativity depends on a number of factors, such as the task and reward. From my studies, I learned that motivation may not be the main factor that leads to creativity, but it is certainly embedded into other factors. Therefore, employers should not overlook their employees’ motivations when using creativity as a measurement unit of performance. 


\section{Appendix A}

\section{RYERSON}

UNIVERSITY

\section{THE PURPOSE:}

\section{Part I - REBUS PUZZLE}

The purpose of this part of the study is to provide you with an opportunity to create puzzles using your own imagination.

\section{EXPECTED DURATION:}

The total anticipated time commitment for Part I will be 15 minutes. The total anticipated time commitment for Part II \& III will be approximately 50 minutes.

\section{VOLUNTARY PARTICIPATION AND WITHDRAWAL:}

Participation in this study is completely voluntary. You can choose whether to be in this study or not. If any task or question makes you uncomfortable, you can exit the task or skip the question. You may stop participating at any time and you will still be given the incentives described above. If you choose to stop participating, your data will not be included in the study unless otherwise stated. Your choice of whether or not to participate will not influence your future relations with Ryerson University or the investigators Sophia Lam, Dr. Fei Song and Dr. Mark Lee who are involved in the research.

\section{INSTRUCTIONS:}

\section{Important Note:}

Please help us maintain control over the experiment by refraining from comments or other communications with your fellow participants in this session between parts/rounds or with other participants who might be participating in future sessions. You will be working individually during the experiment, if you have any questions, kindly raise your hand and we will provide you with assistance.

\section{Introduction - What is a Rebus Puzzle?}

In this experiment, you will be constructing "rebus puzzles". A rebus puzzle is a kind of riddle in which words and/or diagrams are used to represent a familiar term of phrase. Here are some examples: 

1. $\frac{\text { Man }}{\text { Board }}$

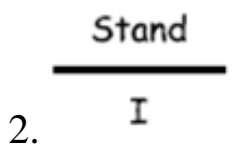

\section{You Just Me}
3.

The above examples use the positioning of the words to create the riddle. The first one is "man over board," because "man" is over "board." The second one is "I understand," for similar reasons. The third example is "just between you can me" (i.e., "just" is between "you" and "me"). Other rebuses use counting, different sizes, shapes, or positions to create the riddle such as these examples:

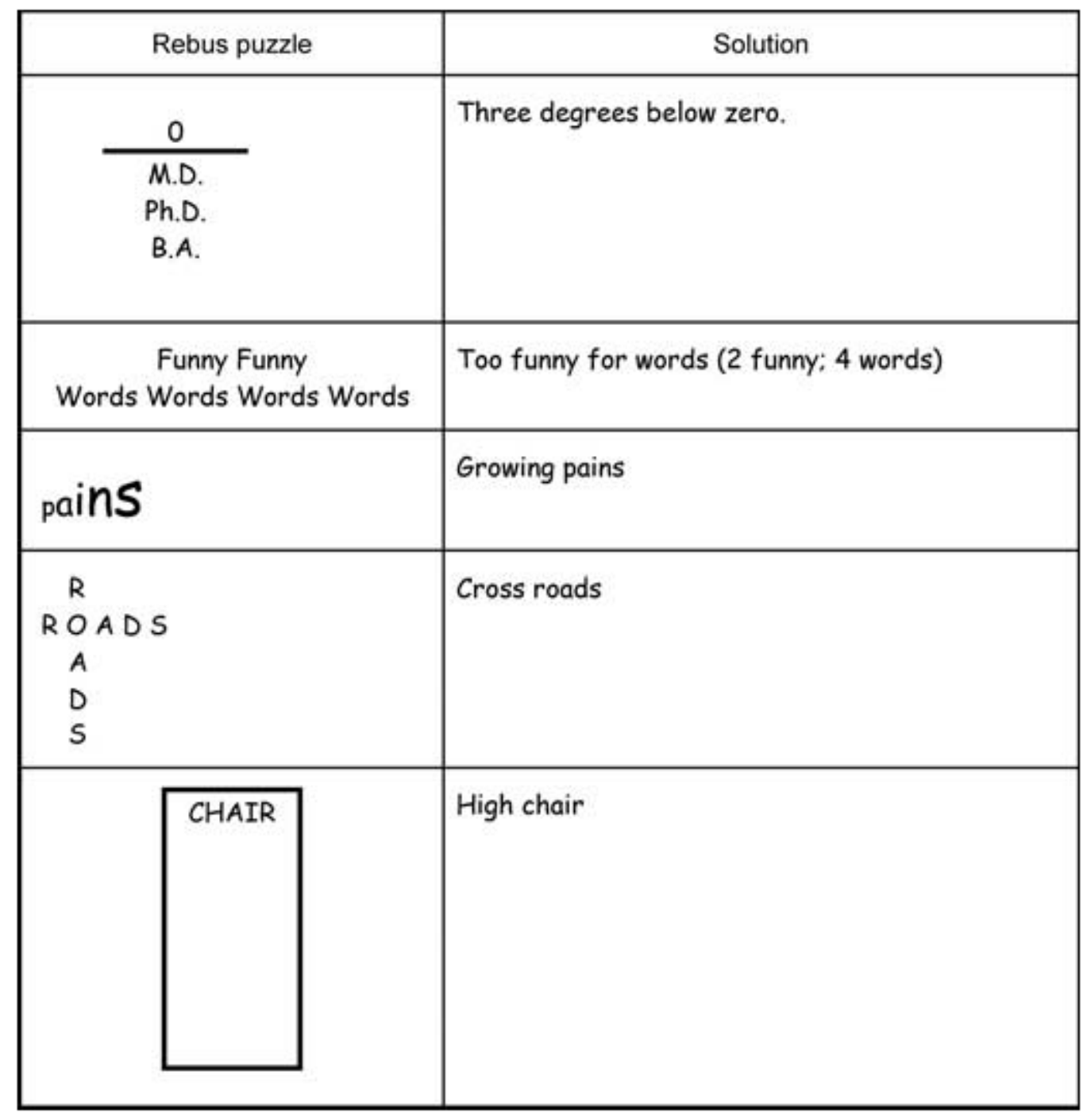


Still other rebuses use simple pictures, symbols, and diagrams as part of the riddle, like these two examples:

\begin{tabular}{|l|l|}
\hline Rebus puzzle & \multicolumn{1}{|c|}{ Solution } \\
\hline BB & A hole in one \\
\hline
\end{tabular}

\section{Task}

At your desk is a stack of blank index cards. Use these cards to construct your own rebus puzzles, putting the puzzle on the front side and the solution on the back side. As you finish each puzzle, please put it in the box provided on your desk. Once you put a puzzle in the box, it is considered finished. Please do not remove any puzzle from the box after you finish them.

While we do not place any rules on the kinds of rebus puzzles you can submit, we value the creativity of those puzzles (i.e., puzzles that are original ideas, innovative, and clever).

There are two parts to the experiment. The first part is for practice where you will have 15 minutes to create 5 puzzles. The intention is to get you familiarize with the game and to evaluate your creativity level based on the puzzles created.

The second part is our main focus. Your creativity score from the previous works along with a goal and a condition will be given to you at the beginning of this part. Your task is to reach the goal under the time pressure.

If you experience any discomfort during the experiment, please raise your hand for assistance. At any time, you are free to leave the experiment either temporary or permanently.

Please ask any questions you might have. When you are ready to proceed, please raise your hand. A researcher will escort you to the experiment room. 


\section{Appendix B}

RYERSON

UNIVERSITY

\section{Part II - Work Preference Inventory}

\section{PURPOSE OF THIS SURVEY:}

The purpose of this part of the study is to assess the intrinsic and extrinsic motivational orientations of participants in the task they have just took part in.

\section{EXPECTED DURATION:}

The total anticipated time commitment will be approximately 15 - 20 minutes

\section{VOLUNTARY PARTICIPATION AND WITHDRAWAL:}

Participation in this study is completely voluntary. You can choose whether to be in this study or not. If any task or question makes you uncomfortable, you can exit the task or skip the question. You may stop participating at any time and you will still be given the incentives described above. If you choose to stop participating, your data will not be included in the study unless otherwise stated. Your choice of whether or not to participate will not influence your future relations with Ryerson University or the investigators Sophia Lam, Dr. Fei Song and Dr. Mark Lee who are involved in the research.

\section{INSTRUCTIONS:}

For each of the following questions, indicate the extent to which each item describes you. Please circle only one letter for each question according to the following scale:

$$
\begin{aligned}
& \mathrm{N}=\text { Never or almost never true of you } \\
& \mathrm{S}=\text { Sometimes true of you } \\
& \mathrm{O}=\text { Often true of you } \\
& \mathrm{A}=\text { Always or almost always true of you }
\end{aligned}
$$

When you complete, please raise your hand. A researcher will come and collect the booklet. You will be compensated accordance to the rule indicated in the Consent Agreement.

\section{Thank you for your participation!}

For each of the following, indicate the extent to which each item describes you based on the work you have just completed. Please circle only one letter for each question according to the following scale: 


$$
\begin{aligned}
& \mathrm{N}=\text { Never or almost never true of you } \\
& \mathrm{S}=\text { Sometimes true of you } \\
& \mathrm{O}=\text { Often true of you } \\
& \mathrm{A}=\text { Always or almost always true of you }
\end{aligned}
$$

1. I am not that concerned about what other people think of my work.

2. I prefer having someone set clear goals for me in my work.

3. The more difficult the problem, the more I enjoy trying to solve it.

4. I am keenly aware of the goals I have for getting the job done/good grades.

5. I want my work to provide me with opportunities for increasing my knowledge and skills.

6. To me, success means doing better than other people.

7. I prefer to figure things out for myself.

$\begin{array}{llll}\mathrm{N} & \mathrm{S} & \mathrm{O} & \mathrm{A}\end{array}$

$\begin{array}{llll}\mathrm{N} & \mathrm{S} & \mathrm{O} & \mathrm{A}\end{array}$

N $\quad \mathrm{S} \quad \mathrm{O} \quad \mathrm{A}$

N $\quad \mathrm{S} \quad \mathrm{O} \quad \mathrm{A}$

N $\quad S \quad O \quad A$

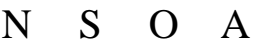

$\begin{array}{llll}\mathrm{N} & \mathrm{S} & \mathrm{O} & \mathrm{A}\end{array}$

8. No matter what the outcome of a project, I am satisfied if I feel I gained a $\quad \begin{array}{lllll}\mathrm{N} & \mathrm{S} & \mathrm{O} & \mathrm{A}\end{array}$ new experience.

9. I enjoy relatively simple, straightforward tasks.

10. I am keenly aware of the goals I have for myself. (Note: not the one given to me by the researcher, if any)

11. Curiosity is the driving force behind much of what I do.

12. I am less concerned with what work I do than what I get for it.

13. I enjoy tackling problems that are completely new to me.

14. I prefer work I know I can do well over work that stretches my abilities.

15. I am concerned about how other people are going to react to my ideas.

16. I seldom think about winning, grades, and awards.

17. I am more comfortable when I can set my own goals.

18. I believe that there is no point in doing a good job if nobody else knows about it.

19. I am strongly motivated by the money I can earn.

20. It is important for me to be able to do what I most enjoy.

21. I prefer working on projects with clearly specified procedures.

22. As long as I can do what I enjoy, I am not that concerned about exactly what I am paid or what grades/awards I earn.

23. I enjoy doing work that is so absorbing that I forget about everything else. $\quad \begin{array}{lllll}\mathrm{N} & \mathrm{S} & \mathrm{O} & \mathrm{A}\end{array}$

24. I am strongly motivated by the recognition I can earn from other people. $\quad \begin{array}{lllll}\mathrm{N} & \mathrm{S} & \mathrm{O} & \mathrm{A}\end{array}$

25. I have to feel that I am earning something for what I do.

26. I enjoy trying to solve complex problems.

27. It is important for me to have an outlet for self-expression.

28. I want to find out how good I really can be at my work.

29. I want other people to find out how good I really can be at my work.

30. What matters most to me is enjoying what I do.
N $\quad S \quad O \quad$ A

$\mathrm{N} \quad \mathrm{S} \quad \mathrm{O} \quad \mathrm{A}$

$\begin{array}{llll}\mathrm{N} & \mathrm{S} & \mathrm{O} & \mathrm{A}\end{array}$

N $\quad \mathrm{S} \quad \mathrm{O} \quad \mathrm{A}$

$\begin{array}{llll}N & S & O & A\end{array}$

$\mathrm{N} \quad \mathrm{S} \quad \mathrm{O}$ A

$\begin{array}{llll}N & S & O & A\end{array}$

N $\quad \mathrm{S} \quad \mathrm{O} \quad \mathrm{A}$

N $\quad \mathrm{S} \quad \mathrm{O} \quad \mathrm{A}$

$\mathrm{N}$ S O A

$\begin{array}{llll}N & S & O & A\end{array}$

N S O A

N $\quad \mathrm{S} \quad \mathrm{O} \quad \mathrm{A}$

N $\quad \mathrm{S} \quad \mathrm{O} \quad \mathrm{A}$

$\begin{array}{llll}\mathrm{N} & \mathrm{S} & \mathrm{O} & \mathrm{A}\end{array}$

$\mathrm{N} \quad \mathrm{S} \quad \mathrm{O}$ A

$\begin{array}{llll}N & S & O & A\end{array}$

N S O A

N $\quad \mathrm{S} \quad \mathrm{O} \quad \mathrm{A}$

N S O A 
Demographic Questions

1. How old are you?

2. What is your gender?

Self-identified as Female

Self- identified as Male

Self- identified as Other

3. Do you make more than minimum wage? As per the Ontario Employment Standard Act (ESA), as of Oct, 2016, the minimum wage is $\$ 11.40$ per hour.

$\square$ YES $\square$ NO

4. What is your professional job title?

5. How long have you been in the position?

Your Experiment ID:

Date:

THE END! 


\section{Appendix C}

\section{Instructions to Participants}

Although it seems like smartphones can do anything these days, every iPhone, Android, or BlackBerry user can think of one thing they wish his/her phone could do. Well, here's your chance!

Come up with your dream application and then create a picture and/or write up a paragraph that describes what the App would do. It could be something quite feasible or something completely out of this world. Maybe you will even be daring enough to try to make your idea into a real app and make millions! Have fun with it.

You will have 30 minutes for this brain-storm exercise. Try to be creative and have fun during this process. 


\section{Instructions to Participants}

Although it seems like smartphones can do anything these days, every iPhone, Android, or BlackBerry user can think of one thing they wish his/her phone could do. Well, here's your chance!

Come up with your dream application and then create a picture and/or write up a paragraph that describes what the App would do. It could be something quite feasible or something completely out of this world. Maybe you will even be daring enough to try to make your idea into a real app and make millions! Have fun with it.

You will have 30 minutes for this brain-storm exercise. Try to be creative and have fun during this process.

Even though research participants normally only earn course credits for participating in a research project, we would like to give you a "token of appreciation", for working hard on your creative App design exercise. We will be giving you a $\$ \underline{\mathbf{5}}$ after you finish and submit your App design at the end of the session. We hope that you will appreciate the surprise gift and in return submit the most creative App design! Thanks!! 


\section{Appendix D}

Participant ID

1. What is you gender? (Please mark one circle with an X)
O Male
O Female
O Prefer not to say

2. What is your age?

3. Where were you born? (Specify one response only, according to present boundaries)

Born in Canada (Specify Province):

Born outside Canada (Specify country):

4. Is English your first language? (Check one.) O Yes O No, my first language is

5. Please read each item carefully and circle the number that best describes the reason why you were engaged in the activity that you just completed. Tick a box on the scale from 1 (not at all for this reason) to 7 (exactly for this reason)"

1) Because I think that this activity was interesting

2) Because I was doing it for my own good

$\begin{array}{lllllll}1 & 2 & 3 & 4 & 5 & 6 & 7\end{array}$

3) Because I was supposed to do it

$\begin{array}{lllllll}1 & 2 & 3 & 4 & 5 & 6 & 7\end{array}$

4) There may be good reasons to do this activity, but personally I don't see any

5) Because I think that this activity was pleasant

$\begin{array}{lllllll}1 & 2 & 3 & 4 & 5 & 6 & 7\end{array}$

$\begin{array}{lllllll}1 & 2 & 3 & 4 & 5 & 6 & 7\end{array}$

6) Because I think that this activity was good for me

$\begin{array}{lllllll}1 & 2 & 3 & 4 & 5 & 6 & 7\end{array}$

7) Because it was something that I had to do

8) I did this activity but I was not sure if it was worth it

9) Because this activity was fun

$\begin{array}{llllllll}1 & 2 & 3 & 4 & 5 & 6 & 7\end{array}$

10) By personal decision

$\begin{array}{llllllll}1 & 2 & 3 & 4 & 5 & 6 & 7\end{array}$

11) Because I didn’t have any choice

$\begin{array}{llllllll}1 & 2 & 3 & 4 & 5 & 6 & 7\end{array}$

12) I don't know; I don't see what this activity brings me

$\begin{array}{llllllll}1 & 2 & 3 & 4 & 5 & 6 & 7\end{array}$

13) Because I felt good when doing this activity

$\begin{array}{lllllll}1 & 2 & 3 & 4 & 5 & 6 & 7\end{array}$

14) Because I believe that this activity was important for me

$$
\begin{array}{lllllll}
1 & 2 & 3 & 4 & 5 & 6 & 7
\end{array}
$$

15) Because I felt that I had to do it

$$
\begin{array}{llllllll}
1 & 2 & 3 & 4 & 5 & 6 & 7
\end{array}
$$

16) I did this activity, but I was not sure it was a good thing to pursue it

$\begin{array}{lllllll}1 & 2 & 3 & 4 & 5 & 6 & 7\end{array}$




\section{Bibliography}

Abbasi, S. M., \& Hollman, K. W. (2000). Turnover: The real bottom line. Public Personnel Management, 29(3), 333-342.

Albrecht, S.L. (Ed.). (2010). Handbook of employee engagement: Perspectives, issues, research and practice. Glos, England: Edward Elgar.

Amabile, T. M., DeJong, W., \& Lepper, M. R. (1976). Effects of externally imposed deadlines on subsequent intrinsic motivation. Journal of Personality and Social Psychology, 34(1), 92.

Amabile, T. M. (1983). The social psychology of creativity: A componential conceptualization. Journal of Personality and Social Psychology, 45(2),357.

Amabile, T. M., Hill, K. G., Hennessey, B. A., \& Tighe, E. M. (1994). The Work Preference Inventory: Assessing intrinsic and extrinsic motivational orientations. Journal of Personality and Social Psychology, 66(5), 950.

Amabile, T. M. (1996). Creativity in context: Update to "the social psychology of creativity." Westview press.

Amabile, T. M., \& Hennessey, B. A. (1998). Reward, intrinsic motivation, and creativity. American Psychologist, 53(6), 674-675.

Amabile, T. M. (1988). A model of creativity and innovation in organizations. Research in Organizational Behavior, 10(1), 123-167.

Andersen, P. K., Borgan, O., Gill, R. D., \& Keiding, N. (2012). Statistical models based on counting processes. Springer Science \& Business Media.

Aktar, S., Sachu, M. K., \& Ali, M. E. (2012). The impact of rewards on employee performance in commercial banks of Bangladesh: An empirical study. Journal of Business and Management, 6(2), 9-15.

Baker, G. P., Jensen, M. C., \& Murphy, K. J. (1988). Compensation and incentives: Practice vs. theory. The Journal of Finance, 43(3), 593-616.

Bakker, A.B., \& Demerouti, E. (2008). Towards a model of work engagement. Career Development International, 13, 209-223.

Baron, R. M., \& Kenny, D. A. (1986). The moderator-mediator variable distinction in social psychological research. Journal of Personality and Social Psychology, 51(6), 1173-1182.

Blaikie, N. (2009). Designing social research. Polity. 
Cadsby, C. B., Song, F., \& Tapon, F. (2007). Sorting and incentive effects of pay for performance: An experimental investigation. Academy of Management Journal, 50(2), 387-405.

Choi, J. N. (2004). Individual and contextual predictors of creative performance: The mediating role of psychological processes. Creativity Research Journal, 16(2-3), 187-199.

Durham, C. C., \& Bartol, K. M. (2000). Pay for performance. Handbook of Principles of Organizational Behavior, 150-165.

Deci, E. L. (1971). Effects of externally mediated rewards on intrinsic motivation. Journal of Personality and Social Psychology, 18(1), 105.

Deci, E. L. (1972). The effects of contingent and noncontingent rewards and controls on intrinsic motivation. Organizational Behavior and Human Performance, 8(2), 217-229.

Deci, E. L., \& Cascio, W. F. (1972). Changes in Intrinsic Motivation as a Function of Negative Feedback and Threats.

Deci, E. L., \& Ryan, RM (1985). Intrinsic motivation and self-determination in human behavior. New York and London: Plenum.

Durham, C. C., \& Bartol, K. M. (2000). Pay for performance. Handbook of Principles of Organizational Behavior, 150-165.

Dzuranin, A., \& Stuart, R. D. (2012). The effect tangible and intangible noncash rewards on performance and satisfaction in a production setting. Management Accounting Quarterly, 13(4), 1-9.

Eby, L. T., Freeman, D. M., Rush, M. C., \& Lance, C. E. (1999). Motivational bases of affective organizational commitment: A partial test of an integrative theoretical model. Journal of Occupational and Organizational Psychology, 72(4), 463-483.

Eisenberger, R. (1992). Learned industriousness. Psychological Review, 99(2), 248.

Eisenberger, R., \& Armeli, S. (1997). Can salient reward increase creative performance without reducing intrinsic creative interest? Journal of Personality and Social Psychology, 72(3), 652.

Eisenberger, R., Rhoades, L., \& Cameron, J. (1999). Does pay for performance increase or decrease perceived self-determination and intrinsic motivation? Journal of Personality and Social Psychology, 77(5), 1026.

Eisenberger, R., Haskins, F., \& Gambleton, P. (1999). Promised reward and creativity: Effects of prior experience. Journal of Experimental Social Psychology, 35(3), 308-325. 
Eisenberger, R., \& Rhoades, L. (2001). Incremental effects of reward on creativity. Journal of Personality and Social Psychology, 81(4), 728.

Eisenberger, R., Stinglhamber, F., Vandenberghe, C., Sucharski, I. L., \& Rhoades, L. (2002). Perceived supervisor support: contributions to perceived organizational support and employee retention. Journal of Applied Psychology, 87(3), 565.

Eisenberger, R., \& Shanock, L. (2003). Rewards, intrinsic motivation, and creativity: A case study of conceptual and methodological isolation. Creativity Research Journal, 15(2-3), 121-130.

Eisenberger, R., \& Aselage, J. (2009). Incremental effects of reward on experienced performance pressure: Positive outcomes for intrinsic interest and creativity. Journal of Organizational Behavior, 95-117.

Fagan, M. H. (2004). The influence of creative style and climate on software development team creativity: an exporatory study. Journal of Computer Information Systems, 44(3), 73-80.

Gagné, M., \& Forest, J. (2008). The study of compensation systems through the lens of selfdetermination theory: Reconciling 35 years of debate (Vol. 49, No. 3, p. 225). Educational Publishing Foundation.

Government of Canada, S. C. (2017, August 4). Average hourly wages of employees by selected characteristics and occupation, unadjusted data, by province (monthly) (Ontario). Retrieved from http://www.statcan.gc.ca/tables-tableaux/sum-som/101/cst01/labr69geng.htm.

Griggs, R. A. (2000) “A One-Minute ‘Intelligence’ Test.” Teaching of Psychology 27: 132-4.

Griffeth, R. W., Hom, P. W., \& Gaertner, S. (2000). A meta-analysis of antecedents and correlates of employee turnover: Update, moderator tests, and research implications for the next millennium. Journal of Management, 26(3), 463-488.

Hausknecht, J. P., Rodda, J., \& Howard, M. J. (2009). Targeted employee retention: Performance-based and job-related differences in reported reasons for staying. Human Resource Management, 48(2), 269-288.

Hennessey, B. A., \& Amabile, T. M. (1988). The conditions of creativity. The Nature of Creativity, 22, 11-38.

Hennessey, B. A., \& Amabile, T. M. (2010). Creativity. Annual Review of Psychology, 61, 569598

Herzberg, F., Mausner, B., \& Snyderman, B. B. (2011). The motivation to work (Vol. 1). Transaction publishers. 
Hull, C. L. (1943). Principles of behavior: An introduction to behavior theory.

Jenkins, G. D. , Jr., Mitra , A., Gupta , N. , and Shaw , J. D. ( 1998 ). Are financial incentives related to performance? A meta - analytic review of empirical research. Journal of Applied Psychology, 83, 777-787.

Kachelmeier, S. J., \& Williamson, M. G. (2010). Attracting Creativity: The Initial and Aggregate Effects of Contract Selection on Creativity-Weighted Productivity. The Accounting Review, 85(5), 1669-1691.

Kahn, W.A. (1990). Psychological conditions of personal engagement and disengagement at work. Academy of Management Journal, 33, 692-724.

Kshelmeier, S. J., Reichert, B. E., \& Williamson, M. G. (2008). Measuring and Motivating Quantity, Creativity, or Both. Journal of Accounting Research, 46(2), 341-373. https://doi.org/10.1111/j.1475-679X.2008.00277.x.

Lawler, E. E. (2000). Pay strategy: New thinking for the new millennium. Compensation \& Benefits Review, 32(1), 7-12.

Locke, E. A., \& Latham, G. P. (1990). Work motivation and satisfaction: Light at the end of the tunnel. Psychological Science, 1(4), 240-246.

Loo, R. (2001). Motivational orientations toward work: An evaluation of the work preference inventory (student form). Measurement and Evaluation in Counseling and Development, 33(4), 222.

March, J.G., \& Simon, H.A. (1958). Organizations. Oxford, England: Wiley.

Malik, M. A. R., Butt, A. N., \& Choi, J. N. (2015). Rewards and employee creative performance: Moderating effects of creative self-efficacy, reward importance, and locus of control. Journal of Organizational Behavior, 36(1), 59-74. https://doi.org/10.1002/job.1943.

McCord, P. (2014, January 1). How Netflix Reinvented HR. Retrieved November 11, 2017, from https://hbr.org/2014/01/how-netflix-reinvented-hr

McElroy, J. C., Morrow, P. C., \& Rude, S. N. (2001). Turnover and organizational performance: a comparative analysis of the effects of voluntary, involuntary, and reduction-in-force turnover. Journal of Applied Psychology, 86(6), 1294.

Milkovich, G. T., Newman, J. M., \& Milkovich, C. (2002). Compensation (Vol. 8). T. Mirror (Ed.). London: McGraw-Hill.

Miller, J. S., Hom, P. W., \& Gomez-Mejia, L. R. (2001). The high cost of low wages: Does maquiladora compensation reduce turnover?. Journal of International Business Studies, 32(3), 585-595. 
Mowday, R. T., Porter, L. W., \& Steers, R. M. (2013). Employee-organization linkages: The psychology of commitment, absenteeism, and turnover. Academic press.

Nickerson, R. S. (1999). Enhancing Creativity. Handbook of Creativity, 392.

Odom, R. Y., Boxx, W. R., \& Dunn, M. G. (1990). Organizational cultures, commitment, satisfaction, and cohesion. Public Productivity \& Management Review, 157-169.

Oldham, G. R., \& Cummings, A. (1996). Employee creativity: Personal and contextual factors at work. Academy of Management Journal, 39(3), 607-634.

PayScale’s 2016 Compensation Best Practices Report. (n.d.). Retrieved October 17, 2016, from https://hub.payscale.com/h/i/221642277-payscales-2016-compensation-best-practicesreport.

Peterson, R. A. (1994). A Meta-Analysis of Cronbach’s Coefficient Alpha. Journal of Consumer Research, 21, 381-91.

Peterson, S. J., \& Luthans, F. (2006). The impact of financial and nonfinancial incentives on business-unit outcomes over time. Journal of Applied Psychology, 91(1), 156.

Pittman, T. S., Davey, M. E., Alafat, K. A., Wetherill, K. V., \& Kramer, N. A. (1980). Informational versus controlling verbal rewards. Personality and Social Psychology Bulletin, 6, 228-233.

Prabhu, V., Sutton, C., \& Sauser, W. (2008). Creativity and certain personality traits: Understanding the mediating effect of intrinsic motivation. Creativity Research Journal, 20(1), 53-66.

Price, J. L., \& Mueller, C. W. (1981). A causal model of turnover for nurses. Academy of Management Journal, 24(3), 543-565.

Porter, L. W., \& Steers, R. M. (1973). Organizational, work, and personal factors in employee turnover and absenteeism. Psychological Bulletin, 80(2), 151.

Powell, I., Montgomery, M., \& Cosgrove, J. (1994). Compensation structure and establishment quit and fire rates. Industrial Relations: A Journal of Economy and Society, 33(2), 229-248.

Putwain, D. W., Kearsley, R., \& Symes, W. (2012). Do creativity self-beliefs predict literacy achievement and motivation? Learning and Individual Differences, 22(3), 370-374.

Ramlall, S. (2004). A review of employee motivation theories and their implications for employee retention within organizations. Journal of American Academy of Business, 5(1/2), 52-63. 
Rhoades, L., Eisenberger, R., \& Armeli, S. (2001). Affective commitment to the organization: The contribution of perceived organizational support. Journal of Applied Psychology, 86(5), 825.

Ryan, R. M. (1982). Control and information in the intrapersonal sphere: An extension of cognitive evaluation theory. Journal of Personality and Social Psychology, 43, 450-461.

Ryan, R. M. (1995). Psychological needs and the facilitation of integrative processes. Journal of Personality, 63(3), 397-427.

Shalley, C. E. (1991). Effects of productivity goals, creativity goals, and personal discretion on individual creativity. Journal of Applied Psychology, 76(2), 179-185. doi:10.1037/00219010.76.2.179.

Shalley, C. E. (1995). Effects of coaction, expected evaluation, and goal setting on creativity and productivity. Academy of Management Journal, 38(2), 483-503.

Shalley, C. E., Gilson, L. L., \& Blum, T. C. (2000). Matching creativity requirements and the work environment: Effects on satisfaction and intentions to leave. Academy of Management Journal, 43(2), 215-223.

Shapira, Z. (1989). Task choice and assigned goals as determinants of task motivation and performance. Organizational Behavior and Human Decision Processes, 44(2), 141-165.

Sternberg, R. J. (1999). Handbook of Creativity. Cambridge University Press.

Stuhlfaut, M. W. (2010). Evaluating the work preference inventory and its measurement of motivation in creative advertising professionals. Journal of Current Issues \& Research in Advertising, 32(1), 81-93.

Thatcher, J. B., Liu, Y., Stepina, L. P., Goodman, J. M., \& Treadway, D. C. (2006). IT worker turnover: An empirical examination of intrinsic motivation. ACM SIGMIS Database, 37(23), 133-146.

Trevor, C. O. (2001). Interactions among actual ease-of-movement determinants and job satisfaction in the prediction of voluntary turnover. Academy of Management Journal, 44(4), 621-638.

Vroom, V. H. (1964). Work and motivation. New York: John Willey \& Sons Inc.

Weibel, A., Rost, K., \& Osterloh, M. (2010). Pay for performance in the public sector: Benefits and (hidden) costs. Journal of Public Administration Research and Theory, 20(2), 387-412.

Wood, R. E., Mento, A. J., \& Locke, E. A. (1987). Task complexity as a moderator of goal effects: A meta-analysis. Journal of Applied Psychology, 72(3), 416. 
Yerkes, R. M., \& Dodson, J. D. (1908). The relation of strength of stimulus to rapidity of habit-formation. Journal of Comparative Neurology, 18(5), 459-482.

Yoon, H. J., Sung, S. Y., Choi, J. N., \& Lee, K. (2015). Tangible and Intangible Rewards and Employee Creativity: The Mediating Role of Situational Extrinsic Motivation. Creativity Research Journal, 27(4), 383. 